\title{
Decomposition of the Shrinking Middle-class and Directional Mobility in Finland 1995-2012
}

\section{Sami Remes ${ }^{1}$ (B)}

Accepted: 5 January 2022 / Published online: 2 February 2022

(c) The Author(s) 2022

\begin{abstract}
This paper investigates the middle-class decline in Finland from 1995 to 2012. The purpose is to examine how changes in the probabilities of belonging to the middle class in different socioeconomic groups have contributed to the middle-class decline while taking into account changes in the relative sizes of the groups. A decomposition analysis indicates that most of the decline has been due to the probability effect, especially among the leasteducated population. Changes in age demographics and educational structure have contributed to the decline. The results of the decomposition are supported by mobility results, which indicate that individuals with a tertiary (no secondary) degree have been subject to upward (downward) mobility over the observed time period. In conclusion, the middleclass decline and polarization in Finland are asymmetrically reflected in different education groups. The highly educated have climbed up the income distribution, while the least educated have fallen.
\end{abstract}

Keywords Decomposition $\cdot$ Income mobility $\cdot$ Middle class

\section{Introduction}

The decline of the middle class has been an ongoing topic in the economics literature since empirical evidence of the phenomenon emerged from the United States in the 1980s and, later, in other industrialized countries. The decline has raised interest among politicians and economists, as a sizable and well-off middle class is presumed to play an important role in an economy. The importance stems from the presumption that the middle class provides political stability, tax revenue, a skilled labor force, investments in human capital, and consumption (e.g. Banerjee and Duflo 2008; Easterly 2001; Galor and Zeira 1993; Thurow 1984).

I am grateful for the Strategic Research Council of Academy of Finland, No. 293120 (STN-WIPconsortium), for providing access to data for this research. Financial support from the Employee Foundation and the Yrjö Jahnsson Foundation are gratefully acknowledged.

Sami Remes

sami.remes@tuni.fi

1 Faculty of Management and Business, Tampere University, Tampere, Finland 
One of the earliest works on the decline of the middle class is Thurow's article in the New York Times, which stated that "the American middle class is disappearing." Thurow defined the middle class as the share of the population with an income between 75 and $125 \%$ of the median and reported a decline in the middle-class population share with shifts towards the tails. While choosing an income range around the median to identify the middle class can be arbitrary, and, in some cases, even affect the results, other studies using alternative income ranges or definitions for the middle-class have found similar results regarding the middle-class decline and the polarization of income distribution. Jenkins (1995) studied the United Kingdom's income distribution using kernel density estimation. Later, Burkhauser et al. (1999) used the same method to compare changes in the US and UK. In addition to the theoretical contributions to statistical inference, Davidson (2018) provided empirical evidence of a middle-class decline in Canada. Empirical evidence of a middle-class decline in Europe emerged slightly later (e.g. Chauvel 2013; Grabka and Frick 2008; Pressman 2007; Riihelä and Tuomala 2019).

Previous studies of the middle-class decline have tended to focus on middle-class identification, empirical evidence of changes between selected years, statistical methodology, and inference. Thus, researchers have debated the best way to define the middle class (e.g., income or other social variables), ways to measure the phenomenon, and how to statistically analyze changes. Considerably less attention has been paid to changes over time and decomposition of the decline to analyze the underlying dynamics of the change and whether the phenomenon affects the population heterogeneously. Interestingly, the direction of the shift in different subgroups has received less attention, even though the direction of the shift has been viewed as important in income distribution studies. These underlying dynamics are of interest, as the middle-class decline can occur due to (i) changes in income development of certain subgroups, or (ii) changes in relative sizes of these subgroups. In both cases, middle class decline can also be due to directional shifts upward in the income distribution, where (i') the likelihood of belonging to a higher income group has increased in certain subgroups or (ii') demographic structure has changed with a relatively higher share of the population belonging to subgroups with higher incomes.

The purpose of this paper is to study the underlying dynamics of the middle-class decline in Finland using a decomposition method that is novel to the income distribution literature. Finland is an interesting case because it is one of the most equal societies in the world, yet studies have shown that Finland experienced an exceptionally pronounced increase in inequality in the 1990s (Jäntti et al. 2010). Nevertheless, the dynamics behind the middle-class decline have received less attention. High-quality register data from Finland allows to examine the dynamics behind middle class decline while taking into account the ongoing demographic changes in Finland.

This paper contributes to the literature in three ways. First, the change in middle-class share is decomposed into subgroup-specific rate-effects (the effect of changes in probability of belonging to the middle-class) and structural change effects (the effect of changes in relative sizes of subgroups). Second, directional income mobility between subgroups is examined to further extend the analysis of the middle-class decline phenomenon. Using national register-based data with over 500,000 annual observations from 1995 to 2012 allows changes to be examined over time instead of only analyzing changes between selected years as most earlier studies have done. Third, a decomposition method proposed by Das Gupta (1978) is utilized that, to the best of the author's knowledge, has not been utilized before in this context. The main benefit of the method is that, due to its additive nature, it allows the overall rate-effect to be examined by subgroup to reveal group-specific contributions to aggregate change while separating the structural change effects into three 
factors. Although the middle-class decline as a population share could be due to shifts towards either tail of the distribution, the mobility analysis has the benefit of distinguishing the direction of the shifts by subgroup.

The results of this study suggest that while structural effects have contributed to the decline of the middle class in Finland, most of the decline is due to decreases in the probability of belonging to the middle class, especially among the population without higher education. The population with higher education has enjoyed a period of upward mobility, which is evident in shifts from low- to middle- and from middle- to high-income groups. The results imply that there are clear asymmetries in how different groups have been affected during the middle-class decline in Finland.

The remainder of this paper is organized as follows. Section 2 describes the method used to identify the middle class and the subgroups and presents baseline estimations of the size of the middle class. Data sources are presented in Sect. 3. Section 4 explains the methodology. Section 5 presents the results from the decomposition of the middle-class decline and mobility analysis. Finally, the main conclusions are summarized in Sect. 6.

\section{The Middle-Class Decline in Finland}

Scholars from different fields have very different views on the defining characteristics of the middle class, and even among economists, there is no consensus on an exact definition of the middle class. Atkinson and Brandolini (2013) examined different ways to identify the middle class. In addition to analyzing changes in the middle class as defined by income from 1985 to 2004, their results and conclusions suggest re-integrating occupation and wealth into the analysis of personal incomes. Although it would be ideal to identify the middle class by all of its characteristics, this is difficult in practice due to the limited availability of data. This is especially true for longer time-series. However, if one decides to include more characteristics in defining the middle class, the choice of which characteristics to include is not necessarily obvious. See Deutsch et al. (2014) for a summary of characteristics of the middle class that have been emphasized in the literature.

Two restrictions, the lack of a consensus on which characteristics to include and limited data availability, led the author to focus on identifying the middle class based on income and income distribution. Households are defined as belonging to the middle class if its equivalized disposable income is within fixed boundaries relative to the country's median income of the current year. A problem that arises from this identification is that the results may vary significantly depending on the chosen set of boundaries (See, e.g. Foster and Wolfson 2010). Naturally, changing either the lower or the upper boundary for the middle class has a direct effect on the population share. The higher (lower) the upper (lower) boundary, the larger the middle-class population share. An obvious advantage of using a commonly used approach in the analysis is comparability with earlier studies.

An estimate of the middle-class population share within a fixed boundary income range reveals how large a share of a population belongs to the middle class. In the analysis, the middle-class population share based on equivalized household disposable income between 75 and $150 \%$ of the median is used. The lower boundary of $75 \%$ was commonly used in earlier studies. According to Atkinson and Brandolini (2013), it defines a margin between the middle class and those at risk of poverty. While this study uses the rather conventional method of defining a lower boundary based on median income, the 'vulnerability approach' proposed by López-Calva and Ortiz-Juarez (2014) 
provides an appealing alternative (For implementation with European data, see Bussolo et al. 2018). In a vulnerability approach, the lower boundary to the middle class is based on an income level with a low associated risk of falling into poverty. Atkinson and Brandolini also discussed justifications for the upper limit, and they claimed that a population share of the rich above one-third is unrealistic. In the current study, the upper limit is set to $150 \%$ of the median, which leaves the size of the well-off between 10 and 20 percent of the population. This definition of the middle class implicitly divides the population into lower and higher income groups with less than $75 \%$ of the median and over $150 \%$ of the median, respectively. Figure 1 presents the development of the population shares of the three income groups (low, middle, and high) in Finland from 1995 to 2012. The overall shape of the curves representing the development is robust to varying the upper boundary for the middle class between 125, 150 and $200 \%$ of the median. Estimates of population shares with alternative upper boundaries are presented in Table 1 in the Appendix.

Figure 1 presents how population share estimates for the three income groups changed from 1995 to 2012 . Using the income range of 75 to $150 \%$ of the median in the current year, $65.8 \%$ of the population belonged to the middle class in 1995. In 2012, the share of the middle class was $56.1 \%$. The total change in the middle class is 9.6 percentage points (hereafter ppt). From 1995 to 2012, the share of the lower class increased from 21.4 to $27.2 \%$. Similarly, the share of the higher class increased from 12.8 to $16.7 \%$. Hence, the share of the lower class increased by $5.8 \mathrm{ppt}$, while the share of the higher class increased by $3.8 \mathrm{ppt}$.

Overall, the estimates presented in this section indicate that the share of the middle class decreased, and the population shifted towards both tails of the income distribution. This shift is evidence of polarization in Finland. In absolute terms, the shift towards the tails was unbalanced, as $62 \%$ of the shifted mass moved into the lower income group, while $38 \%$ moved into the higher income group. In relative terms, the change is more balanced, as the share of the lower income group increased by $27 \%$ and the higher income group by $30 \%$.

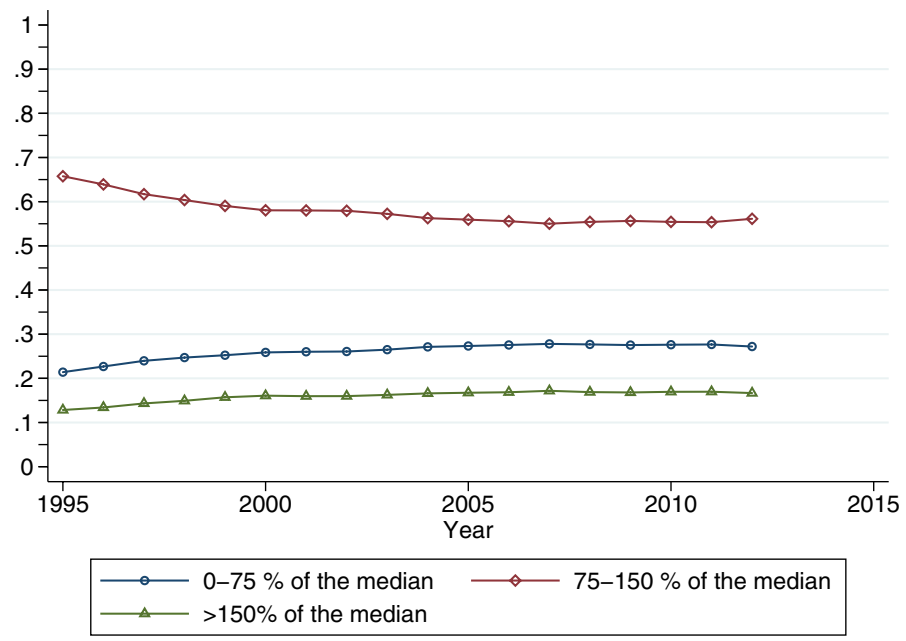

Fig. 1 Population shares of low-, middle-, and high-income groups in Finland from 1995 to 2012. Source: Based on data from Statistics Finland (2014) 
As insightful as estimates for simple population shares are, the results also raise questions regarding the underlying processes. First, changes evident at the population level leave changes at the subgroup level and structure undetected. This encourages studying the overall change by socioeconomic group decomposition. Second, the repeated cross-section analyses described in this section do not account for dynamics at the individual level. The income mobility analysis complements the analysis by focusing entirely on the dynamics and allows examining changes in these dynamics over time and between subgroups.

\subsection{Definition of Socioeconomic Groups}

To examine the underlying processes by analyzing how changes in population structure and individual socioeconomic subgroups contribute to the middle class decline, one first needs to decide on the choice of subgroups and factors to consider. These questions are linked, as socioeconomic groups are defined in terms of chosen factors. To include a factor in the analysis, the chosen factor should be relevant to the overall development and/or able to characterize different subgroups of interest. For example, in an aging population, one could be interested in examining how this structural change has contributed to the overall development. Alternatively, one might want to be able to examine the development of a certain socioeconomic group of interest, e.g., an older workforce with a relatively low education level, which requires the use of more than one factor.

One interesting question to consider is how changes in age demographics have affected the middle class decline. The share of working age in Finland (those aged between 15 to 64) has decreased from 67.0 to $65.1 \%$ - between 1995 and 2012. In addition, the share of population (those younger than 15 years old) has decreased from 19.1 to $16.6 \%$. Meanwhile, the share of population aged 65 and over has increased from 13.9 to $18.3 \%$. While relatively modest changes in absolute terms, these structural shifts in age demographics depicts the aging of the society in Finland. These structural changes can affect the middle class decline, as older groups are less likely to work and are therefore more likely to fall below the lower threshold for middle class. It is also worth noting that age groups together with other factors help to characterize interesting subgroups to examine.

The distribution of educational attainment in Finland has changed significantly from 1995 to 2012. The most striking difference is the increased share of population with at least a tertiary education in Finland. This share has increased by almost three-fold from a mere 5.9 to $15.7 \%$. As this highly educated group is often associated with higher incomes, it is an interesting feature to take into account in decomposition due to structural effects. In addition to the structural effects, the development of different education groups can be of interest in its own right. For instance, have there been changes in how likely different education groups are to belong to the middle class? This could be due to changes in work-life and demand for different skills.

Individuals' primary activities, such as employment and non-employment, are closely related to individuals' incomes and is therefore a seemingly obvious factor to include in the analysis. Naturally, this is of interest when examining the role of structural effects, as the relative sizes of these groups can change. For example, if middle class decline is due to a larger share of the population studying or retired, it could affect how concerned policy makers should be about the development. Including primary activities also allows for examining how changes among various groups in the probability of their belonging to the middle class have contributed to the decline, which in turn might be a more interesting matter. Together with additional factors, the interactions are of particular interest 
when examining, for example, the differences between workers with different amounts of education.

\section{Data}

The panel data used in this study are drawn from Statistics Finland's income distribution statistics. The panel data samples from $10 \%$ of the Finnish population and has over 500,000 annual observations that allow individuals to be tracked over time from 1995 to 2012. The sample is representative, and the number of observations increases over time, as a subset of newborns is included in the data every year. Attrition from the dataset is due to emigration or death. Institutionalized individuals and individuals without an address are not included in the data. The information is gathered from different official register databases. The variables of interest in this study originate from the Population Register Center, Tax Administration, and the Register of Completed Education and Degrees.

The income variable used in this study is disposable, post-tax, and post-transfer household income. This includes wage income, self-employment income, capital income, transfers, and other types of income. Paid taxes and transfers are deducted from income. The disposable household income is then equivalized to account for different household structures using the Organization for Economic Co-operation and Development's (OECD) modified equivalency scale. All household members have the same disposable equivalized household income, and thus the income measure assumes income sharing among household members. Income data are drawn from the tax administration register, which is the most reliable source for income data in Finland. As the measure includes all incomes together, income shifting between wage and capital incomes is not an issue. Naturally, the measure does not capture income that is hidden from the tax administration, whether intentionally or by mistake.

The Register of Completed Education and Degrees has information on individuals' highest degree achieved, which is recorded for eight levels. For the purpose of this study, the education levels were re-coded into three categories: 1 = "no secondary-level degree," 2 = "secondary-level degree," and 3 = "tertiary-level degree." The first group represents individuals with at most a comprehensive/elementary school level of education (no record of completed education of at least level 3 in ISCED 2011), while the second group has completed high school or vocational school (Levels 3-5 in ISCED 2011), and the third group includes individuals with at least a bachelor's-level university degree or a degree from an equivalent institution (Levels 6-8 in ISCED 2011). While the data has a finer categorization of information on education, the re-coding used in this study includes the most relevant groups in Finland. For instance, while tertiary education has become more common in Finland, doctoral degrees are still relatively rare. Hence, the categorization needs to be reasonably detailed related to the context without becoming a burden in the analysis and reporting.

The dataset contains individuals' ages in years. To keep the number of factors reasonable, seven groups are used to categorize the sample and capture the age structure. The first group includes individuals under 15 years old, the second group includes those aged 15-24, the third group 25-34, the fourth group 35-44, the fifth group 45-54, the sixth group 55-64, and the seventh group 65 and older. The 10-year interval length used in this study is a rather fine categorization for the method used. Due to the additivity of the method, one is able to easily transform to a coarser categorization by simply summing up 
the effects (discussed more in Sect. 5). The benefit of a coarser means of categorization is that a smaller number of groups in total allows for easier interpretation and reporting of results for interactions between different factors. Therefore, the choice of categorization involves balancing the depth of details with ease of interpretation and/or reporting. Tables 8 and 7 in the Appendix includes results of the decomposition for the years 2000 and 2012 with age categorized into three classes (0-24, 25-64, and 65 and older).

Primary activity information is based on individuals' primary activity during the last week of the previous year and is recorded at eight levels: $11=$ 'employed,' $12=$ 'unemployed,' 21 = '0-14 years old,' 22 = 'student,' 24 = 'retired,' $25=$ 'military or civil service,' 29 = 'unemployed-retired,' and $99=$ 'others outside of the workforce.' For this study, groups 24 and 29 are combined, as well as groups 25 and 99 . The groups are further assigned new values from 1 to 6 . Values 1, 2, 3, and 4 represent groups 11, 12, 21, and 22, respectively. Groups 24 and 29 each have a value of 5, while groups 25 and 99 are assigned a value of 6 . This relatively fine categorization for main activity is used to a large extent throughout the paper to provide as much detail as possible. In addition, Tables 7 and 8 in the Appendix present results of the decomposition for years 2000 and 2012 with an alternative coarser categorization, where the primary activity is denoted as employed (including group 11) or non-employed (other groups).

\section{Methods}

In randomized experiments, the comparison between two groups is rather straight-forward as in the absence of the treatment groups are alike. But in the social sciences, when studying the differences between two groups or a population at different periods, this is rarely the case. One of the groups or populations might on average be more often employed, have different levels of education, or be older or younger. These differences in population structure need to be accounted for in order to credibly examine the difference in outcomes. Depending on the case, the role of the structural differences itself can be of interest or what remains unexplained after controlling for such differences.

Decomposition methods allow one to take these structural differences into account by dividing the total observed change in outcome into additive contributions from structural differences and differences in group-specific rates. The decomposition method proposed by Das Gupta (1978) and used in this study builds on earlier work by Kitagawa (1955) and Cho et al. (1973). For this study, the main advantages of Das Gupta's decomposition method are that the method allows more factors to be included and doesn't involve a large number of interaction terms between structural effects that are hard to interpret. These interaction terms are caused by simultaneous changes in the different factors, e.g., in age and education structures. The number of these interaction terms increases rapidly as the number of factors is increased (Das Gupta 1993). The decomposition method proposed by Das Gupta accounts for these interaction terms by distributing the interactions evenly among the main effects. In practice, this means that, for example, the joint effects of changes in both age and education structures are evenly divided into the age-structure and education-structure effects taken separately.In general, these effects are quantitatively small and, most importantly, should not change the conclusions about the relative importance of the effects (Das Gupta 1993). In addition to easier interpretation and controlling for the role of structural effects, a very useful property of the method is the additive contributions, 
which allows not only the contributions of the main effects to be examined, but also those at the level of individual groups and factors.

Differences in population structure can also be accounted for in regression-based decomposition approaches. Originating from studies on discrimination, a widely used approach known as the Blinder-Oaxaca decomposition technique divides the group differences into two parts: a part explained by compositional differences and a part that is "attributable to the coefficients" (Blinder 1973; Oaxaca 1973). For this study, as belonging to the middle class is a binary outcome, an extension of the Blinder-Oaxaca technique to a probit model (Fairlie 1999, 2005) is a comparable methodological alternative. Relative to the Blinder-Oaxaca technique with probit coefficients from a pooled sample, an intuitive computation of "explained" compositional effects strongly resembles the computation of structural effects in Das Gupta (1978). Due to these similarities, it would be surprising if the results of the two methods were strikingly different. The decomposition results using this alternative method are presented as a robustness check in Fig. 7 in the Appendix. The results regarding the role of the structural changes are very similar between the two methods, and are not affected by allowing a third degree polynomial form for age in the regression-based method. Overall, they provide confidence in Das Gupta's decomposition method and, on a minor point, that the age categories seem to be sufficient to model the age structure.

In this study, the decomposition method proposed by Das Gupta (1978) is used with three factors defining the socioeconomic groups. The three variables that define an individual's socioeconomic group are his or her education level, age group, and primary activity. In total, using these factors allows, in principle, 126 groups to be identified when groups are based on three education levels, seven age groups, and six different statuses of primary activity. Empirically, we do not observe all groups in the sample. The main benefit of decomposition is that it allows the contribution of main components' group-specific rates and structural changes to be examined separately in three dimensions, defined by the number of factor variables used. Furthermore, it could be of interest to determine which socioeconomic groups are the main drivers of the components.

Following the notation used by Das Gupta (1993), the cell proportions are defined as

$$
\frac{N_{i j k}}{N_{\ldots}}=A_{i j k} B_{i j k} C_{i j k},
$$

where

$$
\begin{gathered}
A_{i j k}=\left(\frac{N_{i j k}}{N_{. j k}}\right)^{\frac{1}{3}}\left(\frac{N_{i j .}}{N_{. j .}} \frac{N_{i . k}}{N_{. . k}}\right)^{\frac{1}{6}}\left(\frac{N_{i . .}}{N_{. . .}}\right)^{\frac{1}{3}}, \\
B_{i j k}=\left(\frac{N_{i j k}}{N_{i . k}}\right)^{\frac{1}{3}}\left(\frac{N_{i j .}}{N_{i . .}} \frac{N_{. j k}}{N_{. . k}}\right)^{\frac{1}{6}}\left(\frac{N_{. j .}}{N_{. .}}\right)^{\frac{1}{3}},
\end{gathered}
$$

and

$$
C_{i j k}=\left(\frac{N_{i j k}}{N_{i j .}}\right)^{\frac{1}{3}}\left(\frac{N_{i . k}}{N_{i . .}} \frac{N_{. j k}}{N_{. j .}}\right)^{\frac{1}{6}}\left(\frac{N_{. . k}}{N_{. . .}}\right)^{\frac{1}{3}} .
$$


$N_{i j k}$ refers to the number of people with a socioeconomic status of $\mathrm{i}, \mathrm{j}$, and $\mathrm{k}$ in the base year, and $N_{. j k}$ is the number of people with a status of $\mathrm{j}$ and $\mathrm{k}$, regardless of $\mathrm{i}$. For instance, $N_{341}$ refers to the number of people in the base year with a tertiary degree who are 35-44 years old and employed. $A_{i j k}, B_{i j k}$, and $C_{i j k}$ reflect the ratios for the structural effects I, J, and $\mathrm{K}$, respectively. Similarly, we compute effect ratios $a_{i j k}, b_{i j k}$, and $c_{i j k}$ for the future time period by replacing each $N_{i j k}$ with the future counterpart $n_{i j k}$.

The change in the middle-class population share is a change in the crude rate of the middle class between two populations or two points in time. The middle-class share at the base population is defined by $S \ldots$ and the future middle-class share by $s . .$. Next, the change in the middle-class population share in terms of the main components or effects is defined:

$$
\begin{aligned}
s \ldots-S \ldots & =R \text {-effect }+I \text {-effect }+J \text {-effect }+K \text {-effect } \\
& =[R(\bar{s})-R(\bar{S})]+[I(\bar{a})-I(\bar{A})]+[J(\bar{b})-J(\bar{B})]+[K(\bar{c})-K(\bar{C})],
\end{aligned}
$$

where

$$
\begin{gathered}
R(\bar{S})=\sum_{i j k} \frac{\frac{n_{i j k}}{n \ldots}+\frac{N_{i j k}}{N_{\ldots}}}{2} S_{i j k}, \\
I(\bar{A})=\sum_{i j k} \frac{s_{i j k}+S_{i j k}}{2}\left[\frac{b_{i j k} c_{i j k}+B_{i j k} C_{i j k}}{3}+\frac{b_{i j k} C_{i j k}+B_{i j k} c_{i j k}}{6}\right] A_{i j k}, \\
J(\bar{B})=\sum_{i j k} \frac{s_{i j k}+S_{i j k}}{2}\left[\frac{a_{i j k} c_{i j k}+A_{i j k} C_{i j k}}{3}+\frac{a_{i j k} C_{i j k}+A_{i j k} c_{i j k}}{6}\right] B_{i j k}, \\
K(\bar{C})=\sum_{i j k} \frac{s_{i j k}+S_{i j k}}{2}\left[\frac{a_{i j k} b_{i j k}+A_{i j k} B_{i j k}}{3}+\frac{a_{i j k} B_{i j k}+A_{i j k} b_{i j k}}{6}\right] C_{i j k},
\end{gathered}
$$

where $S_{i j k}$ and $s_{i j k}$ refer to the middle-class share of the subgroup i, j, and k in the base year and future time period, respectively. $I(\bar{a}), J(\bar{b})$, and $K(\bar{c})$ are computed by replacing the last term with the respective effect ratios $\left(a_{i j k}, b_{i j k}\right.$, and $\left.c_{i j k}\right)$ for $R(\bar{s})$ with the respective crude rate of the non-base population.

In this study, the I-effect term refers to the effect of the change in the education structure. For example, if the education structure has changed due the population mass shifting from lower middle-class-probability educational groups towards groups with a high probability of belonging to the middle class, the I-effect would be positive, which indicates the expected change in middle-class share due to changes in the education structure while keeping education-group-specific probabilities constant. Similarly, the J-effect measures the effect of change in the age structure, keeping age-group-specific probabilities of belonging to the middle-class constant. The K-effect measures the effect of changes in the primary activity structure. The rate-effect depicts the share of the middle-class decline that is due to changes in group-specific probabilities of belonging to the middle class, while keeping the group-specific population shares constant. Hence, this measures the effect that would have occurred if we had only observed changes in probabilities and there were no structural changes. 


\section{Results}

Table 2 presents the results of the decomposition of the change in middle-class share from 1995 to 2012. The results of the decomposition for each year are presented in Table 3 in the Appendix. The results indicate that most of the decrease in the middle-class population share (-9.63 ppt from 1995 to 2012) was driven by decreases in group-specific rates of belonging to the middle class. The rate-effect contribution covers $91.4 \%$ of the observed decrease in the middle-class share. The effect of change in the education structure (I-effect) contributed to the change by $-0.7 \mathrm{ppt}(7.33 \%)$. The effect of change in the age group structure had a similarly-sized contribution as that of the education structure. The effect of change in the primary activity structure on the middle-class share change is positive, which indicates that if group-specific rates and the education and age structures had remained constant, the change in the primary activity structure would have resulted in a higher middle-class population share.

In total, the effects of structural change in education, age groups, and primary activity contributed to the decline in the middle-class share by $8.6 \%$. Intuitively, this means that if we had only observed the change in group-specific rates for middle-class probability, we would expect to see a decrease in the middle-class population share by $8.8 \mathrm{ppt}$. Structural changes in socioeconomic groups overall contributed to the total change by decreasing the middle-class share, but the effect is modest compared to the rate-effect.

The results of decomposition over time did not reveal large anomalies. Figure 2 depicts the timeline of the overall change in the middle-class share, as well as individual components derived from the decomposition. The contribution of the rate-effect remains highly responsible for the overall change. The effect of structural change in education and age groups remains modest and decreases over time. The effect of the primary activity structure, while similarly modest in magnitude, is then of opposite sign and results in more variation over time. The size of the effect increased from 1995 to 2007, when the Finnish

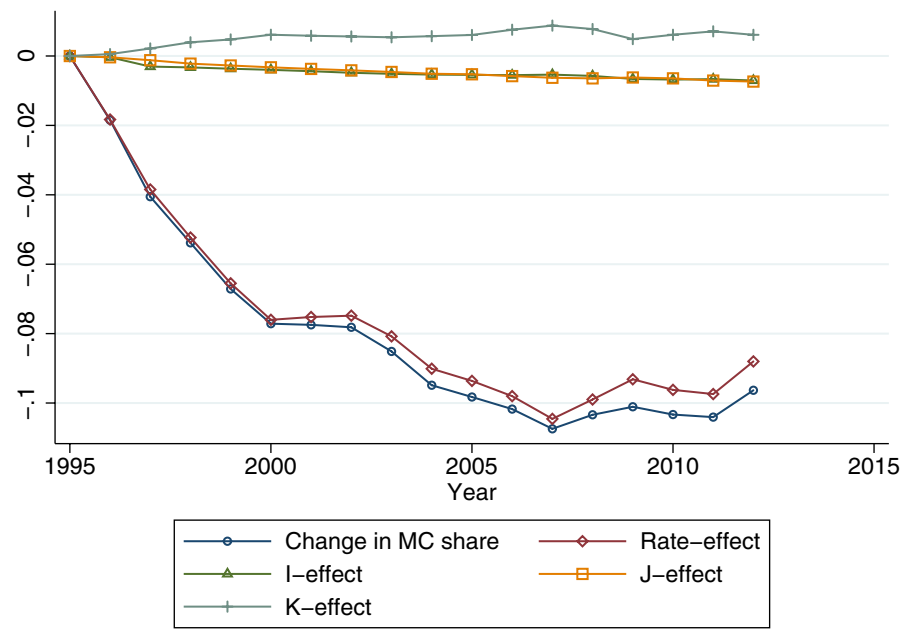

Fig. 2 Decomposition of changes in the middle-class population share into the rate-effect (group-specific rates of belonging to the middle class) and effect of structural changes in education levels (I-effect), age groups (J-effect), and primary activity (K-effect) over time. Source: Based on data from Statistics Finland (2014) 
economy was recovering from a recession and then enjoying a period of growth. The decreased K-effect fits well with the financial crisis period of 2007-2008.

Computed decomposition effects are additively computed across observed socioeconomic groups (Formulas 6-9). This gives a good overview but could raise questions regarding the underlying processes. The additive nature of the decomposition method allows separating the effect into individual groups, but perhaps a more natural step forward would be to compare the contributions of different socioeconomic factors, such as education level, age group, and primary activity. For example, the rate-effect component contributed by education level can be computed by summing the effects of socioeconomic groups with the same education level and allowing the primary activity and age group to vary. This process results in three sub-components for the rate-effect, one for each education level, which can be summed to determine the total rate-effect.

Computing the results by education group tells a more detailed story about which education-level groups are driving the decrease in the middle-class population share in Finland. These results are presented in Table 4 in the Appendix. By 2012, the contribution of the lowest education group (no secondary-level degree) to the rate-effect was -5.84 ppt, which represents $60 \%$ of the total decrease in the middle-class share. The contributions of socioeconomic groups with a secondary degree are $-3.3 \mathrm{ppt}$, and $34 \%$ of the total decrease. The rate-effect for the group with tertiary degrees is positive, at $0.34 \mathrm{ppt}$. Decomposing the rate-effect by education groups then indicates that the rate-effect, which has the higher contribution to the overall decrease, is mainly driven by the rate-effects among the socioeconomic groups with lower education levels. The group with the lowest education level drives the rate-effect the most, while the effect among the highly educated is modest and opposite in direction.

The effects of the structural change in education by education group reveals interesting results. While the overall I-effect is modest, the effects in individual education groups are not. The decrease in population share in the lowest group contributes by decreasing the middle-class share by 7.39 ppt. by 2012 . This effect is mostly mitigated by increases in population share among the higher educated groups, which has a positive contribution to the middle-class share. The structural change in education, where the general level of education is increasing (higher share of population in the more educated groups) has not resulted in an increase in the middle-class share. This result, which is somewhat counterintuitive, is partly due to mobility between middle- and high-income groups in highly-educated groups. The decomposition analysis does not capture this effect, which raises a need to extend the analysis to income group mobility later in Section 5.

The decomposition results by age group are presented in Table 5 in the Appendix. The results by age group for 2012 seem to indicate that the rate-effect is unequally distributed along the age distribution, with younger age groups affected the most. The contribution to the rate-effect is smallest among individuals aged 45 to 54. Although the distribution in the magnitude of age-group-specific rate-effects is uneven, the rate-effect is negative among all age groups. The distribution of the rate-effect by age group remained similar for most of the years. The main anomaly in the results is the rate-effect in the oldest age group in 1996, which is the smallest of the age groups.

The results for the structural effects by age group do not reveal as large and significant results as the analysis by education group. It is worth noting that the J-effect, the effect of change in the age structure, indicates that the population is aging. There are large contributions to the decrease in the J-effect in the 25-34 and 35-44 age groups, while population share increases in the older groups 55-64 and over 64 have the opposite effect. The effect of structural change in primary activity by age group, however, 
indicates that the overall middle-class share increasing contribution is driven by contributions among the older population.

Results by primary activity are presented in the Appendix (Table 6). The rate-effects are negative in all primary activity groups, which indicates that no primary activity group was safe from a decrease in the middle-class rate from 1995 to 2012. The largest absolute rate-effects by primary activity are for group 3 (children aged 0-14) and group 5 (retired). The rate-effect contribution by employed, unemployed, and students are similar in magnitude despite large differences in group sizes. The change in primary activity structure indicates that from 1995 to 2012, the share of employed individuals increased, and the population shares of the unemployed, children, and students decreased.

The decomposition of the rate-effect by socioeconomic factors indicates that the middle class decline has been driven by groups with lower education groups and younger cohorts. While the rate-effect has been negative across the activity groups, the effect has been strongest among children and retired. To further extend the decomposition analysis, one can examine the contributions of the individual subgroups. For example, one may examine the contribution of the employed with a secondary education in the younger cohort. Due to the large number of subgroups in the original analysis and the difficulties it imposes on interpretation and reporting, a coarser set of categorizations has been used for the analysis of individual subgroups.

Results by individual subgroups are presented in the Appendix (Table 7) for 2012. The group with no secondary-level degree who are under 25 years old and nonemployed has the largest contribution to the rate-effect. This group includes children, whose association to the development is likely due to changes in the middle class status of parents and/or main provider in the household. The contribution of this group should be viewed, to a large extent, reflecting the changes that households with children have been facing.

The second and third largest contributing subgroups to the rate-effect and hence to the decline of the middle class are those non-employed and aged 25-64 with either a secondary degree or not, which contribute to the rate-effect by $-1.57 \mathrm{ppt}$ and $-1.46 \mathrm{ppt}$, respectively. Relative to the non-employed in a similar age group with a tertiary degree, where the contribution to the rate-effect is a mere -0.12 , there is striking difference in the absolute contribution. This pattern persists when comparing those employed aged 25-64 of different education levels. The groups with lower education levels negatively contribute to the decline, while the group of those employed aged 25-64 with a tertiary degree has a slightly positive contribution to the rate-effect. However, the employed groups with lower education levels have a smaller contribution than the non-employed. Therefore, higher education or employment seem to protect or mitigate the adverse development. The development in groups containing those aged 25-64 are likely also reflected in the rate-effect of the children mentioned in the previous paragraph.

The decline in the middle class was most apparent in the earlier observation period, from 1995 to 2000, as can be clearly seen in Fig. 2. This distinctive difference in development encourages comparing the decomposition results from 1995 to 2000 and 1995 to 2012. The results using the coarser set of categorizations and individual subgroups for the year 2000 are presented in Table 8 in the Appendix. Similar to the results for 2012, the main contributing subgroup is the group with no secondary-level degree who are under 25 years old and non-employed, while the magnitude of the rate-effect is smaller. Hence, the adverse development associated with this group has persisted and grown larger, but at a slower pace. Continuing with similarities, the development of the non-employed 25-64 age group with lower education levels has been a large contributor to the decline and clearly 
distinct from the development among the tertiary degreed. With two exceptions, the development seems to have simply become stronger from 2000 to 2012.

The two exceptional subgroups are the non-employed elderly with no secondarydegree and the employed aged 25-64 with secondary degrees, where the contribution to the rateeffect is slightly decreased. This implies that incomes in these groups have increased relative to the middle class threshold. In the first group, as this group likely consists of individuals with pension incomes, this could be due to new entrants to the group of those with larger pensions. For the latter group, this increase in incomes (contribution in rate-effect from -0.95 to $-0.71 \mathrm{ppt}$ ) could be due to development in some subset of occupations. To further explore this development, it would be beneficial to have more detailed information on the occupational characteristics.

\subsection{Mobility Between Income Groups}

Income mobility is generally considered a positive force in society, as greater income mobility decreases long-term inequality. For a group of individuals, however, not all mobility is equal. For an individual, income fluctuations, especially unexpected shifts downwards, pose a risk. In this section, the aim is to take directional mobility into account when examining mobility during the period of middle-class decline from 1995 to 2012. Mobility is measured as a share of the population that has experienced a change in their income group to or from the middle class from the previous year. While a relatively crude approach in measuring mobility, an analysis based on flows is straightforward to conduct and a sufficient means of examining the directional aspect. Just as in mobility for individuals, not all flows to or from the middle class are equal. A downward shift from the middle class to the low-income group is certainly a negative trend, but it would be much more difficult to view the shrinking middle class as a problem if it were because everyone in the middle class were shifting upwards. Similarly, increases in the middle-class population share due to inflow from the high-income group are hardly beneficial for the system as a whole.

Upward and downward mobility are examined separately to distinguish the role of directional shifts along the income distribution. When focusing on the middle class, there are four types of flows to examine: low to mid (inflow, upward), mid to high (outflow, upward), high to mid (inflow, downward), and mid to low (outflow, downward). Each of these flows are examined in the full sample, as well as in socioeconomic subgroups, to examine overall mobility. Similarly, as earlier decomposition results extended the analysis of the decreased size of the middle class, mobility in subgroups is examined to extend the directional mobility analysis by revealing the heterogeneity of the effects and highlighting the groups driving the results.

The estimates of the income group changes for the sample population as flows in four categories, along with combined inflows and outflows, are presented in Fig. 3. Estimates for 1996 represent the change from 1995 to 1996. For example, in 1995, 6\% of the population experienced a drop from the middle class to the low-income group while outflow from the lower class to the middle class was $5 \%$, which results in a net outflow towards the left tail from the middle class. At the same time, there has been a net outflow from the middle class to the higher-income group. This polarization of the income classes, shifts from the middle to opposite tails of the distribution, was at its largest in the late 1990s but is still evident during the first decade of the 21st century. Overall, the decreases in population shares of the middle class have been due to net outflows 


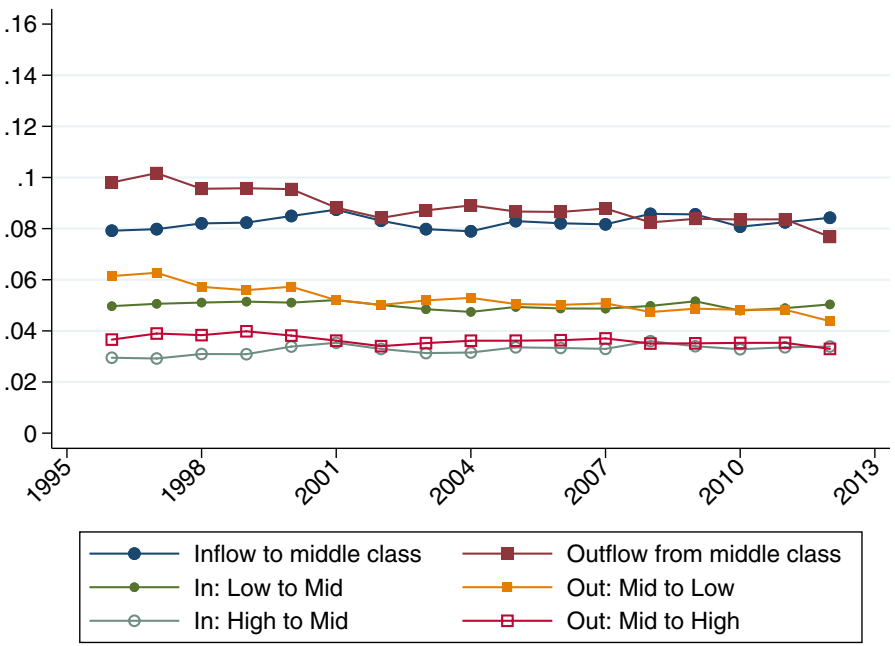

Fig. 3 Directional mobility measured as flows between income groups. The estimates represent the share of the population with a corresponding income-group status change. Source: Based on data from Statistics Finland (2014)

towards both tails of the distribution. This polarization increases income inequality. The increases in inequality are not hindered by income mobility, as the overall level of mobility has not increased.

Despite rather large changes in the late 1990s, the mobility estimates are quite stable overall. However, estimates from the sample population are weighted averages of the effects in various socioeconomic subgroups. Earlier results of the decomposition revealed that the effects can vary significantly between subgroups. If mobility is similarly heterogeneous between subgroups, it raises interest in examining mobility in subgroups determined by socioeconomic factors. Analyses of mobility in subgroups are conducted separately for the following factors: level of education, age group, and primary activity.

Results for mobility by education groups in Fig. 4 reveal that there has been a net outflow from the middle class across all education groups. This development was most evident from 1995 to 2004, followed by a more stable period until 2012. Despite some similarities, there are significant differences in mobility between education groups. For instance, mobility, as shifts to and from the middle class, is at a lower level among the population with no secondary degree compared to the higher-educated proportion of the population.

A further examination of mobility among the population with no secondary degree reveals that most of the shifts happened between low- and middle-income groups. Most of the net outflow from the middle class was due to shifts towards the lower class that lasted from 1995 to 2010 . These results clearly show that during this period, the population with no secondary degree was mainly subjected to downward mobility.

For the population with a secondary degree, the story changes significantly. For this subgroup, the net outflow largely originated from outflow from the middle- to high-income group between 1995 and 2001. Compared to the mobility among the non-secondary degree population, the overall level of mobility was higher due to the level of shifts between the two higher-income groups. Despite the net outflow towards the left tail in the first few years of the observed period, mobility should be interpreted as upward mobility. However, this period of upward mobility seems to have ceased during the 21 st century. 

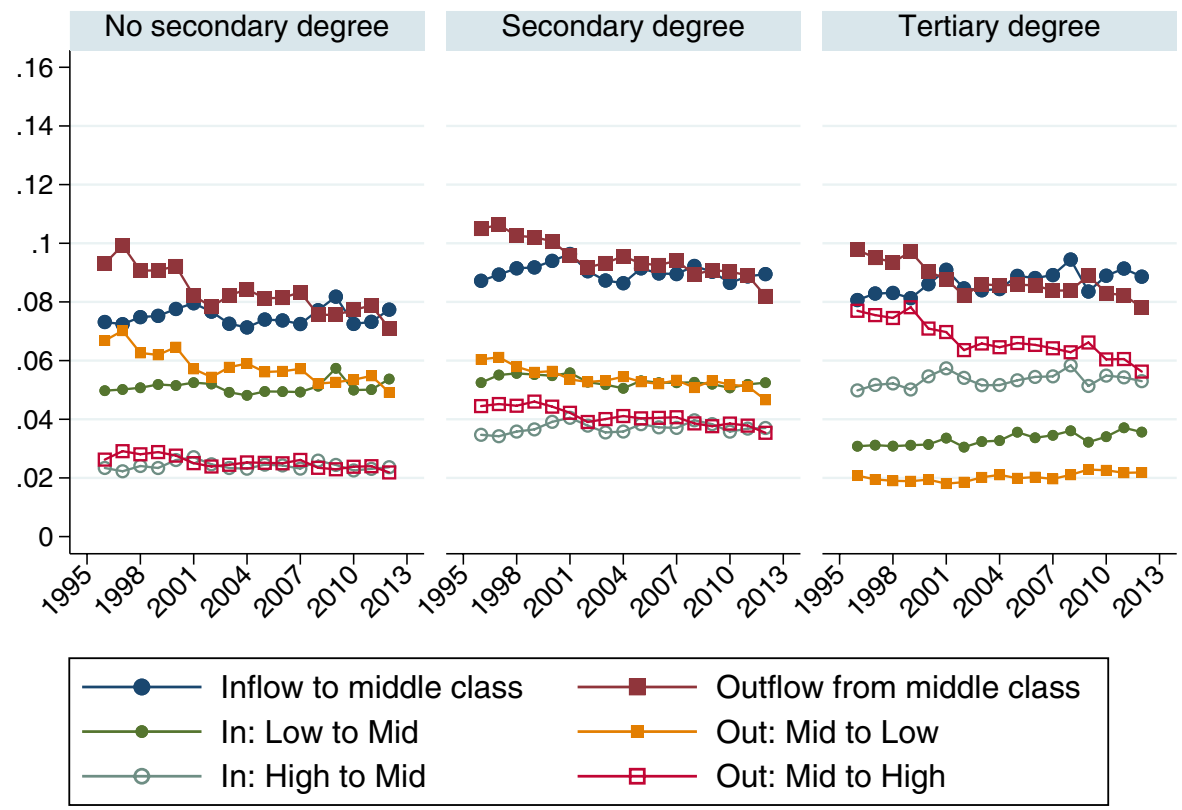

Graphs by education

Fig. 4 Directional mobility by primary activity. Flows are measured as the share of individuals with a corresponding change in income group status. Estimates are relative to the size of an education group. Source: Based on data from Statistics Finland (2014)

The subgroup of those with a tertiary degree experienced upward mobility over the whole period. This is evident in shifts from the low- to middle-income group, as well as from the middle- to high-income group. Contrary to mobility in the least-educated groups, in this subgroup, most of the income group changes occurred between the middle- and high-income groups. The net inflow from the low-income group to the middle class was stable over the whole period, while the net outflow from the middle class to the high-income group decreased over the years. The decreasing net outflow to the highincome group and stable inflow from the left tail of the distribution resulted in a positive net inflow to the middle class from 2005 onward.

Computing the mobility measures by age group reveals that while the effects are heterogeneous between age groups, changes in mobility within age groups over time were modest (Fig. 5). In addition, differences in mobility between age groups could be greatly driven by the life-cycle. When the results are interpreted from the life-cycle perspective, the results indicate clearly distinguishable phases of life: polarization during childhood, possibly driven by parents' income (0-14), shifts between low- and middleincome groups while pursuing higher education and entering the workforce (15-24), upward mobility in young adulthood (24-35), polarizing adulthood (35-44), upward mobility among the well-off during ages 45-54, and downward mobility in older age groups (55-64 and over 65). The level of mobility seems to increase rapidly during the education phase and then decrease over time.

An illustration of changes in the mobility of primary activity groups over time is presented in Fig. 6 in the Appendix. There are significant but mostly unsurprising 
differences between the groups. Both the unemployed and 'outside of the workforce' groups have experienced downward mobility, and most of the overall outflow from the middle class was due to net outflow towards the low-income group. Despite a similarly large net outflow from the mid- to low-income group among students, the story is different due to the simultaneous net outflow from the middle- to high-income group. Therefore, the increased mobility among students was more polarizing. For the employed, the most surprising result is that increased mobility was rather stable over time. While overall inflow to and outflow from the middle class remained stable and seem to fluctuate around a stable mean, the separation to shifts downwards and upwards reveals that the employed enjoyed a period of upward mobility over the whole observed period.

In conclusion, the results from the decomposition revealed that the decreased population share of the middle class is largely driven by the rate-effect, which means that groupspecific probabilities of belonging to the middle class decreased. Meanwhile, the effects of structural changes in education, age, and primary activity are modest, and in the case of primary activity, opposite in sign. Further investigation of the rate-effect revealed that two of the lower education groups are most affected. These results are further strengthened by the mobility analysis, which shows that the population with no secondary degree was subject to downward mobility. However, the population with secondary or tertiary degrees was more likely to shift between middle- and high-income groups, and outflow from the middle class was mostly driven by upward mobility. The implications of these results, as well as the advantages and disadvantages of the methodology, will be discussed in the following section.

\section{Discussion and Conclusions}

This paper set out to investigate the dynamics of the middle-class decline in Finland between 1995 and 2012. The aim of the study was to assess the contributions of individual subgroups based on socioeconomic factors and the role of structural change. In addition, a mobility analysis was conducted to extend the analysis and reveal possible asymmetries in directional mobility by education level, age group, and primary activity.

The most obvious finding to emerge from this study is that group-specific rates were the main driver of the observed middle-class decline in Finland. The rate-effect was most distinct among the population with lower levels of education. However, the effect among employed groups is smaller. The changes in education- and age-structures further contributed to the decline, while the structural change in primary activity status had a counteracting effect. In addition to the structural changes having opposite effects, their contribution to the overall decline was less than 10 percent. The second major finding was the relationship between directional mobility and education level. Among the population without a secondary degree, the rate-effect contribution was driven by downward mobility (shifts from the middle class to the low-income group). While the contribution to the rate-effect from the population with a tertiary degree was low, the directional mobility analysis revealed that there was upward mobility from the low-income group to the middle class, but the effect on the size of the middle class was mitigated by a simultaneous outflow from the middle class to the high-income group.

Taken together, these results suggest that the decomposition of the change and directional mobility by subgroup should be accounted for when investigating the middle-class decline. Although the effects of structural changes were small in this study, 
they could be more relevant in longer time series or other countries. It is important to distinguish the direction of the change behind the middle-class decline. When the middle class is identified by an income range, the middle-class decline could be due to middle-class households shifting upwards along the income distribution, which one might want to separate from downward shifts. Additionally, we can observe a stable middle class with proportionate shifts downwards or upwards along the income distribution or, in the case of different subgroups, moving in opposite directions. The former requires tracking the sizes of all income groups, while the latter requires examining the changes and contributions by subgroup, which also leads one to consider decomposition methods.

This work contributes to existing knowledge of the Finnish middle-class decline in several ways. First, the middle class in Finland has declined mainly due to decreases in probabilities of belonging to the middle class among populations with a lower level of education. Second, structural changes in education, age, and primary activity do not explain much of the middle-class decline in Finland. Third, the direction of shifts from the middle class seems to be associated with education level. Thus, this suggests a lower middle-class consensus due to a smaller middle-class size and more divergent groups along the income distribution.

The limitations of the study should be considered when interpreting the results. The major limitation of this study is that the direction and channels of causality are unclear. It is likely that there are omitted factors driving the results, especially in the case of education and mobility. The decomposition analysis simply indicates the association of factors with the middle class decline but doesn't elaborate on the reasons for the association. For example, the contribution of lower education groups to the middle class decline could be due to changes in how different skills are valued and compensated for in the work-life. Additionally, regarding results on the role of structural effects, it is noteworthy that the used structural distributions are correlated. For instance, an aging society would be reflected in individuals being more often retired and less likely to be in school. However, as the main driving force for the middle class decline is the rateeffect, this is unlikely to affect the main result. The study would also benefit from more detailed employment information. For example, while it is possible to account for structural change in primary activity, the data lack the information needed to analyze the effect of changes in job descriptions or tasks. This is a common problem when data are originally gathered for other purposes, such as income taxation. For an analysis of income mobility, it would be ideal to have more sophisticated measures to analyze subgroup mobility. While there are more advanced measures of income mobility, they were deemed unsuitable for the scope of this study.

Further studies regarding the middle-class decline should continue to investigate the phenomenon in greater detail and include effects within subgroups. This line of research would also benefit from improved statistical measures to analyze sub-populations and provide estimates of statistical inference, especially in smaller samples. The role of structural effects, while marginal in this study, could be more relevant in longer time series or other countries; these effects should be of interest themselves and not just controlled for. One possible future extension to the mobility analysis would be to utilize more formal regression-based methods. Additionally, the middle-class' wellbeing could be an interesting extension of the literature on the middle-class decline. In this study, as in many others, the analysis was based on income, which is at best an incomplete proxy for well-being. 


\section{Tables and figures}

See Tables 1, 2, 3, 4, 5, 6, 7, 8 and Figs. 5 and 6.

Table 1 Income group population shares, including alternative income ranges relative to the median income identifying the middle class

\begin{tabular}{|c|c|c|c|c|c|c|c|c|}
\hline Year & $0-75 \%$ & $75-125 \%$ & $75-150 \%$ & $75-200 \%$ & over $125 \%$ & over $150 \%$ & over $200 \%$ & $\mathrm{n}$ \\
\hline 1995 & .214 & .523 & .658 & .751 & .263 & .128 & .035 & 504709 \\
\hline 1996 & .227 & .503 & .639 & .737 & .27 & .134 & .036 & 504449 \\
\hline 1997 & .24 & .483 & .617 & .718 & .277 & .143 & .042 & 505624 \\
\hline 1998 & .247 & .47 & .604 & .707 & .283 & .149 & .046 & 506491 \\
\hline 1999 & .252 & .46 & .59 & .695 & .288 & .157 & .053 & 507532 \\
\hline 2000 & .259 & .45 & .58 & .686 & .291 & .161 & .055 & 508098 \\
\hline 2001 & .26 & .448 & .58 & .687 & .292 & .16 & .052 & 509608 \\
\hline 2002 & .261 & .447 & .579 & .687 & .292 & .16 & .053 & 510636 \\
\hline 2003 & .265 & .44 & .572 & .68 & .295 & .163 & .055 & 511698 \\
\hline 2004 & .271 & .432 & .563 & .671 & .297 & .166 & .057 & 513001 \\
\hline 2005 & .273 & .428 & .559 & .668 & .299 & .167 & .059 & 515106 \\
\hline 2006 & .276 & .425 & .556 & .665 & .299 & .169 & .059 & 516900 \\
\hline 2007 & .278 & .42 & .55 & .66 & .302 & .172 & .062 & 519249 \\
\hline 2008 & .277 & .424 & .554 & .664 & .299 & .169 & .059 & 521664 \\
\hline 2009 & .275 & .426 & .557 & .667 & .299 & .168 & .058 & 523858 \\
\hline 2010 & .276 & .424 & .554 & .664 & .3 & .17 & .06 & 526049 \\
\hline 2011 & .277 & .423 & .554 & .663 & .3 & .17 & .06 & 527773 \\
\hline 2012 & .272 & .43 & .561 & .671 & .298 & .167 & .057 & 530471 \\
\hline
\end{tabular}

Note Asymptotic standard errors are omitted due to being negligibly small. For example, the estimate of the population share with an income between $75 \%$ and $150 \%$ of the median in 2012 is 0.561 , and the asymptotic standard error is 0.0007

Table 2 Decomposition of the change in the middle-class population share between 1995 and 2012

\begin{tabular}{lll}
\hline Component of the decompositon & Effects & $\begin{array}{l}\text { Percent } \\
\text { distribution of } \\
\text { effects }\end{array}$ \\
\hline Rate-effect (I,J,K) - standardized & -8.8 & 91.36 \\
I-effect (Education) (R,J,K) - standardized & -0.71 & 7.33 \\
J-effect (Age) (R,I,K) - standardized & -0.74 & 7.65 \\
K-effect (Primary status) (R,I,J) - standardized & 0.61 & -6.34 \\
Total effect & -9.63 & 100.0 \\
\hline
\end{tabular}


Table 3 Decomposition of change in the middle-class share, $\Delta \mathrm{MC}$, into Rate-, I-, J, and K-effect in percentage-points. Effect-specific contribution rates $\mathrm{R} \%, \mathrm{I} \%, \mathrm{~J} \%$, and $\mathrm{K} \%$ are computed as the percentage share of $\Delta \mathrm{MC}$, respectively

\begin{tabular}{lllllllllll}
\hline Year & NMC & Rate & $\mathrm{R} \%$ & I-effect & $\mathrm{I} \%$ & $\mathrm{~J}$-effect & $\mathrm{J} \%$ & $\mathrm{~K}$-effect & $\mathrm{K} \%$ & $\mathrm{n}$ \\
\hline 1995 & 0 & 0 & & 0 & & 0 & & 0 & & \\
1996 & -1.85 & -1.83 & 99.02 & -.04 & 1.95 & -.04 & 1.99 & .05 & -2.96 & 504449 \\
1997 & -4.05 & -3.85 & 94.88 & -.3 & 7.5 & -.12 & 2.99 & .22 & -5.36 & 505624 \\
1998 & -5.38 & -5.23 & 97.15 & -.33 & 6.11 & -.22 & 4.07 & .39 & -7.32 & 506491 \\
1999 & -6.71 & -6.55 & 97.59 & -.37 & 5.45 & -.27 & 4.07 & .48 & -7.11 & 507532 \\
2000 & -7.71 & -7.6 & 98.56 & -.4 & 5.17 & -.33 & 4.22 & .61 & -7.95 & 508098 \\
2001 & -7.75 & -7.52 & 97.09 & -.44 & 5.65 & -.37 & 4.8 & .58 & -7.53 & 509608 \\
2002 & -7.82 & -7.48 & 95.73 & -.48 & 6.19 & -.41 & 5.29 & .56 & -7.21 & 510636 \\
2003 & -8.51 & -8.08 & 94.9 & -.51 & 6.03 & -.46 & 5.41 & .54 & -6.33 & 511698 \\
2004 & -9.49 & -9.01 & 94.99 & -.54 & 5.65 & -.51 & 5.39 & .57 & -6.03 & 513001 \\
2005 & -9.83 & -9.36 & 95.28 & -.54 & 5.53 & -.53 & 5.36 & .61 & -6.17 & 515106 \\
2006 & -10.17 & -9.8 & 96.32 & -.55 & 5.42 & -.58 & 5.69 & .76 & -7.44 & 516900 \\
2007 & -10.74 & -10.46 & 97.33 & -.54 & 4.99 & -.63 & 5.83 & .88 & -8.16 & 519249 \\
2008 & -10.34 & -9.9 & 95.74 & -.57 & 5.55 & -.64 & 6.23 & .78 & -7.52 & 521664 \\
2009 & -10.11 & -9.32 & 92.16 & -.66 & 6.54 & -.62 & 6.13 & .49 & -4.83 & 523858 \\
2010 & -10.33 & -9.62 & 93.12 & -.68 & 6.58 & -.64 & 6.23 & .61 & -5.93 & 526049 \\
2011 & -10.41 & -9.74 & 93.62 & -.67 & 6.41 & -.71 & 6.8 & .71 & -6.83 & 527773 \\
2012 & -9.63 & -8.8 & 91.36 & -.71 & 7.33 & -.74 & 7.65 & .61 & -6.34 & 530471 \\
\hline
\end{tabular}


Table 4 Decomposition of change in the middle-class share into rate-, I-, J-, and K-effect by education level

\begin{tabular}{|c|c|c|c|c|c|c|}
\hline Year & Education & Rate-effect & I-effect & J-effect & K-effect & $\mathrm{n}$ \\
\hline 1995 & 1 & 0 & 0 & 0 & 0 & 278455 \\
\hline 1995 & 2 & 0 & 0 & 0 & 0 & 196519 \\
\hline 1995 & 3 & 0 & 0 & 0 & 0 & 29735 \\
\hline 1996 & 1 & -1.03 & -.61 & .03 & -.03 & 273588 \\
\hline 1996 & 2 & -.73 & .44 & -.06 & .07 & 199701 \\
\hline 1996 & 3 & -.07 & .14 & -.01 & .01 & 31160 \\
\hline 1997 & 1 & -2.49 & -1.1 & .04 & -.05 & 269912 \\
\hline 1997 & 2 & -1.36 & -.07 & -.13 & .22 & 196536 \\
\hline 1997 & 3 & .01 & .87 & -.04 & .04 & 39176 \\
\hline 1998 & 1 & -3.31 & -1.5 & .05 & -.15 & 266069 \\
\hline 1998 & 2 & -1.88 & .17 & -.2 & .47 & 199514 \\
\hline 1998 & 3 & -.04 & .99 & -.06 & .08 & 40908 \\
\hline 1999 & 1 & -4.08 & -1.93 & .07 & -.21 & 262747 \\
\hline 1999 & 2 & -2.35 & .41 & -.26 & .59 & 201819 \\
\hline 1999 & 3 & -.12 & 1.16 & -.08 & .09 & 42966 \\
\hline 2000 & 1 & -4.78 & -2.39 & .1 & -.23 & 258838 \\
\hline 2000 & 2 & -2.7 & .63 & -.33 & .73 & 203906 \\
\hline 2000 & 3 & -.12 & 1.37 & -.09 & .12 & 45354 \\
\hline 2001 & 1 & -4.8 & -2.88 & .12 & -.26 & 255713 \\
\hline 2001 & 2 & -2.65 & .82 & -.39 & .72 & 205858 \\
\hline 2001 & 3 & -.07 & 1.62 & -.1 & .12 & 48037 \\
\hline 2002 & 1 & -4.78 & -3.39 & .13 & -.27 & 252259 \\
\hline 2002 & 2 & -2.68 & .99 & -.43 & .71 & 207432 \\
\hline 2002 & 3 & -.03 & 1.91 & -.11 & .13 & 50945 \\
\hline 2003 & 1 & -5.2 & -3.85 & .15 & -.3 & 248664 \\
\hline 2003 & 2 & -2.86 & 1.12 & -.48 & .7 & 209011 \\
\hline 2003 & 3 & -.03 & 2.22 & -.13 & .13 & 54023 \\
\hline 2004 & 1 & -5.72 & -4.27 & .14 & -.32 & 245271 \\
\hline 2004 & 2 & -3.26 & 1.23 & -.52 & .75 & 210626 \\
\hline 2004 & 3 & -.03 & 2.51 & -.13 & .15 & 57104 \\
\hline 2005 & 1 & -6 & -4.68 & .14 & -.3 & 242763 \\
\hline 2005 & 2 & -3.37 & 1.34 & -.53 & .76 & 212249 \\
\hline 2005 & 3 & .01 & 2.79 & -.14 & .15 & 60094 \\
\hline 2006 & 1 & -6.27 & -5.02 & .12 & -.31 & 239834 \\
\hline 2006 & 2 & -3.56 & 1.4 & -.56 & .89 & 213833 \\
\hline 2006 & 3 & .03 & 3.07 & -.14 & .17 & 63233 \\
\hline 2007 & 1 & -6.75 & -5.27 & .09 & -.36 & 237370 \\
\hline 2007 & 2 & -3.8 & 1.39 & -.57 & 1.04 & 215466 \\
\hline 2007 & 3 & .09 & 3.35 & -.15 & .2 & 66413 \\
\hline 2008 & 1 & -6.52 & -5.65 & .08 & -.41 & 234989 \\
\hline 2008 & 2 & -3.55 & 1.32 & -.58 & .97 & 216040 \\
\hline 2008 & 3 & .17 & 3.75 & -.15 & .21 & 70635 \\
\hline 2009 & 1 & -6 & -6.21 & .09 & -.44 & 232166 \\
\hline 2009 & 2 & -3.43 & 1.52 & -.55 & .76 & 218105 \\
\hline 2009 & 3 & .11 & 4.03 & -.16 & .17 & 73587 \\
\hline 2010 & 1 & -6.12 & -6.6 & .08 & -.45 & 229300 \\
\hline
\end{tabular}


Table 4 (continued)

\begin{tabular}{lllllll}
\hline Year & Education & Rate-effect & I-effect & J-effect & K-effect & $\mathrm{n}$ \\
\hline 2010 & 2 & -3.66 & 1.6 & -.55 & .87 & 219905 \\
2010 & 3 & .16 & 4.32 & -.18 & .2 & 76844 \\
2011 & 1 & -6.3 & -6.96 & .08 & -.46 & 226249 \\
2011 & 2 & -3.69 & 1.68 & -.59 & .96 & 221636 \\
2011 & 3 & .25 & 4.61 & -.19 & .21 & 79888 \\
2012 & 1 & -5.84 & -7.39 & .08 & -.5 & 224029 \\
2012 & 2 & -3.3 & 1.76 & -.6 & .9 & 223363 \\
2012 & 3 & .34 & 4.93 & -.21 & .2 & 83079 \\
\hline
\end{tabular}


Table 5 Decomposition of change in the middle-class share into rate-, I-, J-, and K-effect by age-group

\begin{tabular}{|c|c|c|c|c|c|c|}
\hline Year & Age-group & Rate-effect & I-effect & J-effect & K-effect & $\mathrm{n}$ \\
\hline 1995 & 1 & 0 & 0 & 0 & 0 & 96468 \\
\hline 1995 & 2 & 0 & 0 & 0 & 0 & 62388 \\
\hline 1995 & 3 & 0 & 0 & 0 & 0 & 71672 \\
\hline 1995 & 4 & 0 & 0 & 0 & 0 & 78341 \\
\hline 1995 & 5 & 0 & 0 & 0 & 0 & 68112 \\
\hline 1995 & 6 & 0 & 0 & 0 & 0 & 57570 \\
\hline 1995 & 7 & 0 & 0 & 0 & 0 & 70158 \\
\hline 1996 & 1 & -.56 & -.08 & 0 & 0 & 95892 \\
\hline 1996 & 2 & -.26 & .01 & .09 & -.04 & 62696 \\
\hline 1996 & 3 & -.34 & .05 & -.31 & .03 & 69760 \\
\hline 1996 & 4 & -.3 & .04 & -.17 & .03 & 77486 \\
\hline 1996 & 5 & -.22 & 0 & .34 & .01 & 71003 \\
\hline 1996 & 6 & -.14 & -.03 & -.07 & .01 & 56964 \\
\hline 1996 & 7 & -.01 & -.02 & .07 & .02 & 70648 \\
\hline 1997 & 1 & -.97 & -.14 & -.03 & -.03 & 95093 \\
\hline 1997 & 2 & -.54 & -.04 & .24 & 0 & 63561 \\
\hline 1997 & 3 & -.62 & .06 & -.6 & .09 & 68086 \\
\hline 1997 & 4 & -.47 & .02 & -.4 & .11 & 76659 \\
\hline 1997 & 5 & -.34 & -.05 & .5 & .06 & 73033 \\
\hline 1997 & 6 & -.3 & -.1 & .01 & -.03 & 57749 \\
\hline 1997 & 7 & -.62 & -.04 & .15 & .02 & 71443 \\
\hline 1998 & 1 & -1.28 & -.21 & -.09 & -.09 & 93966 \\
\hline 1998 & 2 & -.72 & -.05 & .55 & -.12 & 64716 \\
\hline 1998 & 3 & -.78 & .09 & -.98 & .19 & 65973 \\
\hline 1998 & 4 & -.71 & .05 & -.62 & .25 & 76165 \\
\hline 1998 & 5 & -.55 & -.04 & .56 & .18 & 74605 \\
\hline 1998 & 6 & -.43 & -.12 & .11 & -.01 & 58936 \\
\hline 1998 & 7 & -.74 & -.06 & .25 & .01 & 72130 \\
\hline 1999 & 1 & -1.6 & -.27 & -.11 & -.11 & 93269 \\
\hline 1999 & 2 & -.9 & -.05 & .63 & -.16 & 64967 \\
\hline 1999 & 3 & -1 & .12 & -1.2 & .22 & 64728 \\
\hline 1999 & 4 & -.93 & .08 & -.77 & .3 & 75529 \\
\hline 1999 & 5 & -.64 & -.04 & .48 & .2 & 74435 \\
\hline 1999 & 6 & -.54 & -.14 & .36 & -.01 & 61371 \\
\hline 1999 & 7 & -.95 & -.07 & .34 & .03 & 73233 \\
\hline 2000 & 1 & -1.75 & -.33 & -.13 & -.13 & 92653 \\
\hline 2000 & 2 & -.9 & -.06 & .63 & -.18 & 64658 \\
\hline 2000 & 3 & -1.16 & .15 & -1.36 & .27 & 63944 \\
\hline 2000 & 4 & -1.13 & .11 & -.94 & .36 & 74652 \\
\hline 2000 & 5 & -.71 & -.03 & .33 & .25 & 73590 \\
\hline 2000 & 6 & -.67 & -.16 & .73 & -.01 & 64691 \\
\hline 2000 & 7 & -1.28 & -.07 & .41 & .04 & 73910 \\
\hline 2001 & 1 & -1.84 & -.4 & -.13 & -.13 & 92370 \\
\hline 2001 & 2 & -1.01 & -.07 & .59 & -.19 & 64085 \\
\hline 2001 & 3 & -1.17 & .18 & -1.49 & .24 & 63388 \\
\hline 2001 & 4 & -1.08 & .13 & -1.06 & .33 & 74105 \\
\hline
\end{tabular}


Table 5 (continued)

\begin{tabular}{|c|c|c|c|c|c|c|}
\hline Year & Age-group & Rate-effect & I-effect & J-effect & K-effect & $\mathrm{n}$ \\
\hline 2001 & 5 & -.63 & -.03 & .2 & .24 & 72741 \\
\hline 2001 & 6 & -.68 & -.18 & 1.06 & .01 & 67966 \\
\hline 2001 & 7 & -1.11 & -.08 & .47 & .09 & 74953 \\
\hline 2002 & 1 & -1.89 & -.46 & -.15 & -.15 & 91866 \\
\hline 2002 & 2 & -1.1 & -.09 & .5 & -.15 & 63754 \\
\hline 2002 & 3 & -1.18 & .23 & -1.64 & .22 & 62687 \\
\hline 2002 & 4 & -1.09 & .16 & -1.13 & .31 & 73750 \\
\hline 2002 & 5 & -.6 & -.02 & .05 & .21 & 71413 \\
\hline 2002 & 6 & -.65 & -.21 & 1.4 & 0 & 71137 \\
\hline 2002 & 7 & -.97 & -.1 & .56 & .12 & 76029 \\
\hline 2003 & 1 & -1.97 & -.52 & -.18 & -.18 & 91086 \\
\hline 2003 & 2 & -1.23 & -.1 & .49 & -.14 & 63768 \\
\hline 2003 & 3 & -1.2 & .27 & -1.78 & .21 & 62088 \\
\hline 2003 & 4 & -1.15 & .19 & -1.21 & .29 & 73511 \\
\hline 2003 & 5 & -.69 & -.02 & -.15 & .2 & 69990 \\
\hline 2003 & 6 & -.71 & -.23 & 1.68 & .01 & 73843 \\
\hline 2003 & 7 & -1.12 & -.1 & .68 & .15 & 77412 \\
\hline 2004 & 1 & -2.07 & -.58 & -.2 & -.2 & 90534 \\
\hline 2004 & 2 & -1.39 & -.11 & .49 & -.13 & 63724 \\
\hline 2004 & 3 & -1.3 & .31 & -1.82 & .21 & 62173 \\
\hline 2004 & 4 & -1.24 & .2 & -1.4 & .29 & 72414 \\
\hline 2004 & 5 & -.79 & -.02 & -.27 & .2 & 69180 \\
\hline 2004 & 6 & -.84 & -.24 & 1.89 & .02 & 76003 \\
\hline 2004 & 7 & -1.39 & -.09 & .8 & .17 & 78973 \\
\hline 2005 & 1 & -2.13 & -.64 & -.25 & -.25 & 89704 \\
\hline 2005 & 2 & -1.47 & -.1 & .39 & -.01 & 64001 \\
\hline 2005 & 3 & -1.34 & .35 & -1.8 & .19 & 62621 \\
\hline 2005 & 4 & -1.28 & .21 & -1.56 & .25 & 71307 \\
\hline 2005 & 5 & -.73 & -.02 & -.34 & .17 & 68567 \\
\hline 2005 & 6 & -.94 & -.26 & 2.18 & .02 & 78724 \\
\hline 2005 & 7 & -1.47 & -.08 & .85 & .24 & 80182 \\
\hline 2006 & 1 & -2.17 & -.69 & -.29 & -.29 & 88861 \\
\hline 2006 & 2 & -1.48 & -.12 & .42 & .03 & 64233 \\
\hline 2006 & 3 & -1.4 & .38 & -1.78 & .23 & 63377 \\
\hline 2006 & 4 & -1.34 & .23 & -1.8 & .29 & 69891 \\
\hline 2006 & 5 & -.8 & -.01 & -.47 & .2 & 67886 \\
\hline 2006 & 6 & -1.03 & -.26 & 2.26 & .03 & 79775 \\
\hline 2006 & 7 & -1.58 & -.08 & 1.07 & .28 & 82877 \\
\hline 2007 & 1 & -2.26 & -.74 & -.32 & -.32 & 88264 \\
\hline 2007 & 2 & -1.48 & -.13 & .48 & .01 & 64368 \\
\hline 2007 & 3 & -1.43 & .42 & -1.71 & .26 & 64540 \\
\hline 2007 & 4 & -1.41 & .24 & -2.06 & .33 & 68443 \\
\hline 2007 & 5 & -.79 & 0 & -.57 & .23 & 67560 \\
\hline 2007 & 6 & -1.16 & -.26 & 2.5 & .06 & 82456 \\
\hline 2007 & 7 & -1.94 & -.06 & 1.07 & .31 & 83618 \\
\hline
\end{tabular}


Table 5 (continued)

\begin{tabular}{|c|c|c|c|c|c|c|}
\hline Year & Age-group & Rate-effect & I-effect & J-effect & K-effect & $\mathrm{n}$ \\
\hline 2008 & 1 & -2.29 & -.8 & -.35 & -.35 & 87888 \\
\hline 2008 & 2 & -1.44 & -.14 & .51 & -.08 & 64273 \\
\hline 2008 & 3 & -1.37 & .45 & -1.6 & .23 & 66074 \\
\hline 2008 & 4 & -1.31 & .24 & -2.35 & .29 & 66713 \\
\hline 2008 & 5 & -.72 & 0 & -.64 & .21 & 67412 \\
\hline 2008 & 6 & -1.07 & -.28 & 2.59 & .11 & 84032 \\
\hline 2008 & 7 & -1.71 & -.05 & 1.19 & .37 & 85272 \\
\hline 2009 & 1 & -2.32 & -.86 & -.36 & -.36 & 87594 \\
\hline 2009 & 2 & -1.63 & -.15 & .43 & -.06 & 64313 \\
\hline 2009 & 3 & -1.39 & .49 & -1.57 & .1 & 66646 \\
\hline 2009 & 4 & -1.28 & .25 & -2.46 & .14 & 65797 \\
\hline 2009 & 5 & -.69 & .01 & -.67 & .09 & 66985 \\
\hline 2009 & 6 & -1 & -.3 & 2.67 & .12 & 85594 \\
\hline 2009 & 7 & -1.01 & -.1 & 1.32 & .46 & 86929 \\
\hline 2010 & 1 & -2.36 & -.92 & -.36 & -.36 & 87454 \\
\hline 2010 & 2 & -1.7 & -.18 & .46 & -.03 & 64503 \\
\hline 2010 & 3 & -1.49 & .52 & -1.59 & .13 & 66783 \\
\hline 2010 & 4 & -1.29 & .28 & -2.6 & .16 & 65171 \\
\hline 2010 & 5 & -.76 & .02 & -.76 & .09 & 66410 \\
\hline 2010 & 6 & -1 & -.3 & 2.63 & .11 & 85631 \\
\hline 2010 & 7 & -1.03 & -.1 & 1.58 & .51 & 90097 \\
\hline 2011 & 1 & -2.42 & -.98 & -.33 & -.33 & 87583 \\
\hline 2011 & 2 & -1.66 & -.19 & .52 & -.07 & 64558 \\
\hline 2011 & 3 & -1.43 & .56 & -1.67 & .14 & 66498 \\
\hline 2011 & 4 & -1.28 & .3 & -2.71 & .19 & 64813 \\
\hline 2011 & 5 & -.78 & .02 & -.84 & .12 & 66165 \\
\hline 2011 & 6 & -1.01 & -.3 & 2.46 & .11 & 84563 \\
\hline 2011 & 7 & -1.16 & -.08 & 1.87 & .56 & 93593 \\
\hline 2012 & 1 & -2.28 & -1.04 & -.32 & -.32 & 87799 \\
\hline 2012 & 2 & -1.64 & -.21 & .51 & -.09 & 64602 \\
\hline 2012 & 3 & -1.31 & .57 & -1.71 & .09 & 66652 \\
\hline 2012 & 4 & -1.16 & .32 & -2.83 & .13 & 64389 \\
\hline 2012 & 5 & -.66 & .02 & -.86 & .08 & 66323 \\
\hline 2012 & 6 & -.89 & -.29 & 2.28 & .11 & 83417 \\
\hline 2012 & 7 & -.87 & -.08 & 2.2 & .62 & 97289 \\
\hline
\end{tabular}


Table 6 Decomposition of change in the middle-class share into rate-, I-, J-, and K-effect by activity

\begin{tabular}{|c|c|c|c|c|c|c|}
\hline Year & Activity & Rate-effect & I-effect & J-effect & K-effect & $\mathrm{n}$ \\
\hline 1995 & 1 & 0 & 0 & 0 & 0 & 192873 \\
\hline 1995 & 2 & 0 & 0 & 0 & 0 & 47111 \\
\hline 1995 & 3 & 0 & 0 & 0 & 0 & 96468 \\
\hline 1995 & 4 & 0 & 0 & 0 & 0 & 45017 \\
\hline 1995 & 5 & 0 & 0 & 0 & 0 & 106133 \\
\hline 1995 & 6 & 0 & 0 & 0 & 0 & 17107 \\
\hline 1996 & 1 & -.63 & .07 & -.05 & .23 & 195121 \\
\hline 1996 & 2 & -.21 & .01 & -.01 & -.12 & 45882 \\
\hline 1996 & 3 & -.56 & -.08 & 0 & 0 & 95892 \\
\hline 1996 & 4 & -.22 & -.01 & 0 & -.16 & 43559 \\
\hline 1996 & 5 & -.08 & -.03 & .02 & .04 & 106380 \\
\hline 1996 & 6 & -.13 & 0 & -.01 & .06 & 17615 \\
\hline 1997 & 1 & -.79 & -.02 & -.17 & 1.12 & 203073 \\
\hline 1997 & 2 & -.59 & -.02 & 0 & -.78 & 39600 \\
\hline 1997 & 3 & -.97 & -.14 & -.03 & -.03 & 95093 \\
\hline 1997 & 4 & -.41 & -.03 & .02 & -.1 & 44095 \\
\hline 1997 & 5 & -.88 & -.09 & .07 & -.02 & 106295 \\
\hline 1997 & 6 & -.21 & 0 & -.01 & .04 & 17468 \\
\hline 1998 & 1 & -1.17 & .05 & -.28 & 2.23 & 212433 \\
\hline 1998 & 2 & -.86 & -.01 & -.01 & -1.08 & 36641 \\
\hline 1998 & 3 & -1.28 & -.21 & -.09 & -.09 & 93966 \\
\hline 1998 & 4 & -.53 & -.04 & .05 & -.57 & 40117 \\
\hline 1998 & 5 & -1.12 & -.11 & .13 & -.13 & 105936 \\
\hline 1998 & 6 & -.27 & 0 & -.02 & .03 & 17398 \\
\hline 1999 & 1 & -1.5 & .09 & -.41 & 2.67 & 216487 \\
\hline 1999 & 2 & -1.01 & -.01 & -.01 & -1.28 & 34533 \\
\hline 1999 & 3 & -1.6 & -.27 & -.11 & -.11 & 93269 \\
\hline 1999 & 4 & -.66 & -.04 & .06 & -.73 & 38608 \\
\hline 1999 & 5 & -1.42 & -.13 & .24 & -.16 & 106670 \\
\hline 1999 & 6 & -.36 & 0 & -.03 & .09 & 17965 \\
\hline 2000 & 1 & -1.69 & .14 & -.53 & 3.3 & 221912 \\
\hline 2000 & 2 & -1.14 & -.02 & -.01 & -1.61 & 30993 \\
\hline 2000 & 3 & -1.75 & -.33 & -.13 & -.13 & 92653 \\
\hline 2000 & 4 & -.72 & -.04 & .05 & -.77 & 38085 \\
\hline 2000 & 5 & -1.93 & -.14 & .34 & -.24 & 106778 \\
\hline 2000 & 6 & -.37 & 0 & -.03 & .06 & 17677 \\
\hline 2001 & 1 & -1.63 & .18 & -.65 & 3.27 & 222682 \\
\hline 2001 & 2 & -1.13 & -.02 & -.03 & -1.64 & 30731 \\
\hline 2001 & 3 & -1.84 & -.4 & -.13 & -.13 & 92370 \\
\hline 2001 & 4 & -.76 & -.05 & .02 & -.79 & 37729 \\
\hline 2001 & 5 & -1.75 & -.16 & .46 & -.17 & 108461 \\
\hline 2001 & 6 & -.41 & 0 & -.04 & .06 & 17635 \\
\hline 2002 & 1 & -1.59 & .24 & -.77 & 3.24 & 223140 \\
\hline 2002 & 2 & -1.11 & -.02 & -.02 & -1.76 & 29552 \\
\hline 2002 & 3 & -1.89 & -.46 & -.15 & -.15 & 91866 \\
\hline 2002 & 4 & -.85 & -.06 & .01 & -.63 & 39066 \\
\hline
\end{tabular}


Table 6 (continued)

\begin{tabular}{lllllll}
\hline Year & Activity & Rate-effect & I-effect & J-effect & K-effect & $\mathrm{n}$ \\
\hline 2002 & 5 & -1.62 & -.19 & .57 & -.2 & 109357 \\
2002 & 6 & -.43 & 0 & -.05 & .06 & 17655 \\
2003 & 1 & -1.73 & .28 & -.88 & 3.19 & 223687 \\
2003 & 2 & -1.14 & -.01 & -.03 & -1.74 & 29648 \\
2003 & 3 & -1.97 & -.52 & -.18 & -.18 & 91086 \\
2003 & 4 & -.93 & -.06 & .01 & -.61 & 39102 \\
2003 & 5 & -1.86 & -.19 & .68 & -.22 & 110179 \\
2003 & 6 & -.46 & 0 & -.06 & .09 & 17996 \\
2004 & 1 & -1.9 & .31 & -1.01 & 3.27 & 225273 \\
2004 & 2 & -1.26 & -.01 & -.02 & -1.75 & 29124 \\
2004 & 3 & -2.07 & -.58 & -.2 & -.2 & 90534 \\
2004 & 4 & -1.02 & -.07 & 0 & -.6 & 39155 \\
2004 & 5 & -2.27 & -.18 & .77 & -.22 & 111115 \\
2004 & 6 & -.48 & 0 & -.06 & .07 & 17800 \\
2005 & 1 & -1.83 & .34 & -1.1 & 3.12 & 225313 \\
2005 & 2 & -1.3 & -.01 & -.02 & -1.86 & 27877 \\
2005 & 3 & -2.13 & -.64 & -.25 & -.25 & 89704 \\
2005 & 4 & -1.08 & -.07 & .02 & -.31 & 41771 \\
2005 & 5 & -2.49 & -.18 & .87 & -.1 & 113316 \\
2005 & 6 & -.53 & .01 & -.06 & 0 & 17125 \\
2006 & 1 & -1.87 & .39 & -1.22 & 3.62 & 230123 \\
2006 & 2 & -1.37 & -.02 & -.02 & -2.18 & 24191 \\
2006 & 3 & -2.17 & -.69 & -.29 & -.29 & 88861 \\
2006 & 4 & -1.1 & -.07 & .03 & -.3 & 41967 \\
2006 & 5 & -2.75 & -.17 & .99 & -.11 & 114560 \\
2006 & 6 & -.54 & .01 & -.07 & .01 & 17198 \\
2007 & 1 & -1.88 & .44 & -1.29 & 4.09 & 235326 \\
2007 & 2 & -1.37 & -.02 & -.03 & -2.44 & 21407 \\
2007 & 3 & -2.26 & -.74 & -.32 & -.32 & 88264 \\
2007 & 4 & -1.11 & -.07 & .04 & -.42 & 40808 \\
2007 & 5 & -3.25 & -.15 & 1.04 & -.04 & 116086 \\
2007 & 6 & -.6 & .01 & -.07 & .01 & 17358 \\
2008 & 1 & -1.75 & .47 & -1.36 & 4.04 & 236526 \\
2008 & 2 & -1.17 & -.02 & -.06 & -2.39 & 22760 \\
2008 & 3 & -2.29 & -.8 & -.35 & -.35 & 87888 \\
2008 & 4 & -1.08 & -.08 & .04 & -.55 & 39541 \\
2008 & 5 & -3 & -.15 & 1.15 & .04 & 117855 \\
2008 & 6 & -.61 & 0 & -.07 & -.02 & 17094 \\
2009 & 1 & -1.77 & .5 & -1.46 & 2.77 & 227940 \\
2009 & 2 & -1.18 & 0 & -.08 & -1.76 & 29315 \\
2009 & 3 & -2.32 & -.86 & -.36 & -.36 & 87594 \\
2009 & 4 & -1.21 & -.09 & .03 & -.39 & 41124 \\
2009 & 5 & -2.18 & -.22 & 1.31 & .21 & 120469 \\
2009 & 6 & -.66 & .01 & -.07 & .01 & 17416 \\
2010 & 1 & -1.76 & .56 & -1.61 & 3.06 & 231228 \\
\hline & & & & & &
\end{tabular}


Table 6 (continued)

\begin{tabular}{lllllll}
\hline Year & Activity & Rate-effect & I-effect & J-effect & K-effect & $\mathrm{n}$ \\
\hline 2010 & 2 & -1.37 & -.01 & -.07 & -1.99 & 26263 \\
2010 & 3 & -2.36 & -.92 & -.36 & -.36 & 87454 \\
2010 & 4 & -1.25 & -.1 & .03 & -.37 & 41296 \\
2010 & 5 & -2.21 & -.22 & 1.42 & .23 & 122205 \\
2010 & 6 & -.67 & .01 & -.07 & .03 & 17603 \\
2011 & 1 & -1.6 & .63 & -1.77 & 3.33 & 233964 \\
2011 & 2 & -1.44 & -.01 & -.08 & -2.08 & 24907 \\
2011 & 3 & -2.42 & -.98 & -.33 & -.33 & 87583 \\
2011 & 4 & -1.25 & -.11 & .02 & -.46 & 40338 \\
2011 & 5 & -2.37 & -.2 & 1.52 & .24 & 123642 \\
2011 & 6 & -.66 & 0 & -.07 & .01 & 17339 \\
2012 & 1 & -1.26 & .67 & -1.9 & 3.03 & 232522 \\
2012 & 2 & -1.32 & 0 & -.11 & -1.86 & 27585 \\
2012 & 3 & -2.28 & -1.04 & -.32 & -.32 & 87799 \\
2012 & 4 & -1.25 & -.13 & .01 & -.48 & 40138 \\
2012 & 5 & -2.02 & -.2 & 1.67 & .24 & 125220 \\
2012 & 6 & -.66 & 0 & -.08 & 0 & 17207 \\
\hline
\end{tabular}

Table 7 Decomposition of change in the middle-class share into rate-, I-, J-, and K-effect by individual groups with a coarser categorization for year 2012 (base 1995). Age is divided into 3-classes 0-24, 25-64 and over 65. Activity defined as employed or non-employed

\begin{tabular}{lllllllll}
\hline Year & Education & $\begin{array}{l}\text { Age-group } \\
\text { 3-class }\end{array}$ & Employed & Rate-effect & I-effect & J-effect & K-effect & $\mathrm{n}$ \\
\hline 2012 & 1 & 1 & 0 & -2.97 & -1.16 & -.19 & -.48 & 116492 \\
2012 & 1 & 1 & 1 & -.11 & -.14 & .17 & .08 & 4625 \\
2012 & 1 & 2 & 0 & -1.46 & -1.38 & -.45 & -.59 & 23686 \\
2012 & 1 & 2 & 1 & -.51 & -2.93 & -.55 & .28 & 26423 \\
2012 & 1 & 3 & 0 & -.79 & -1.75 & 1.05 & .18 & 52092 \\
2012 & 1 & 3 & 1 & 0 & -.04 & .05 & .03 & 711 \\
2012 & 2 & 1 & 0 & -.54 & -.11 & -.06 & -.5 & 12250 \\
2012 & 2 & 1 & 1 & -.28 & .04 & .24 & .48 & 17220 \\
2012 & 2 & 2 & 0 & -1.57 & .61 & -.16 & -1.22 & 40260 \\
2012 & 2 & 2 & 1 & -.71 & .06 & -1.56 & 1.77 & 119297 \\
2012 & 2 & 3 & 0 & -.2 & 1.15 & .89 & .34 & 33305 \\
2012 & 2 & 3 & 1 & 0 & .02 & .05 & .03 & 1031 \\
2012 & 3 & 1 & 0 & -.01 & .03 & 0 & -.01 & 481 \\
2012 & 3 & 1 & 1 & -.01 & .09 & .03 & .02 & 1333 \\
2012 & 3 & 2 & 0 & -.12 & .69 & -.06 & -.18 & 9745 \\
2012 & 3 & 2 & 1 & .35 & 3.58 & -.34 & .33 & 61370 \\
2012 & 3 & 3 & 0 & .12 & .53 & .15 & .04 & 9638 \\
2012 & 3 & 3 & 1 & 0 & .01 & .01 & .01 & 512 \\
\hline
\end{tabular}


Table 8 Decomposition of change in the middle-class share into rate-, I-, J-, and K-effect by individual groups with a coarser categorization for year 2000 (base 1995). Age is recorded with 3-classes 0-24, 25-64 and over 65 . Activity defined as employed or non-employed

\begin{tabular}{lllllllll}
\hline Year & Education & $\begin{array}{l}\text { Age-group } \\
\text { 3-class }\end{array}$ & Employed & Rate-effect & I-effect & J-effect & K-effect & $\mathrm{n}$ \\
\hline 2000 & 1 & 1 & 0 & -2.13 & -.39 & -.02 & -.55 & 118735 \\
2000 & 1 & 1 & 1 & -.07 & 0 & .2 & .23 & 6983 \\
2000 & 1 & 2 & 0 & -.99 & -.51 & -.11 & -.6 & 34535 \\
2000 & 1 & 2 & 1 & -.48 & -1.12 & -.27 & .68 & 43901 \\
2000 & 1 & 3 & 0 & -1.11 & -.37 & .28 & -.01 & 54181 \\
2000 & 1 & 3 & 1 & 0 & 0 & .01 & .02 & 503 \\
2000 & 2 & 1 & 0 & -.31 & -.02 & .03 & -.41 & 15167 \\
2000 & 2 & 1 & 1 & -.13 & -.03 & .26 & .42 & 15340 \\
2000 & 2 & 2 & 0 & -1.12 & .23 & -.08 & -1.03 & 38823 \\
2000 & 2 & 2 & 1 & -.95 & .27 & -.65 & 1.71 & 118894 \\
2000 & 2 & 3 & 0 & -.19 & .19 & .1 & .03 & 15457 \\
2000 & 2 & 3 & 1 & 0 & 0 & .01 & .01 & 225 \\
2000 & 3 & 1 & 0 & 0 & .02 & .01 & -.01 & 347 \\
2000 & 3 & 1 & 1 & 0 & .03 & .02 & .01 & 739 \\
2000 & 3 & 2 & 0 & -.07 & .21 & -.02 & -.11 & 5481 \\
2000 & 3 & 2 & 1 & -.07 & 1 & -.12 & .23 & 35243 \\
2000 & 3 & 3 & 0 & .01 & .11 & .01 & 0 & 3460 \\
2000 & 3 & 3 & 1 & 0 & 0 & 0 & 0 & 84 \\
\hline
\end{tabular}



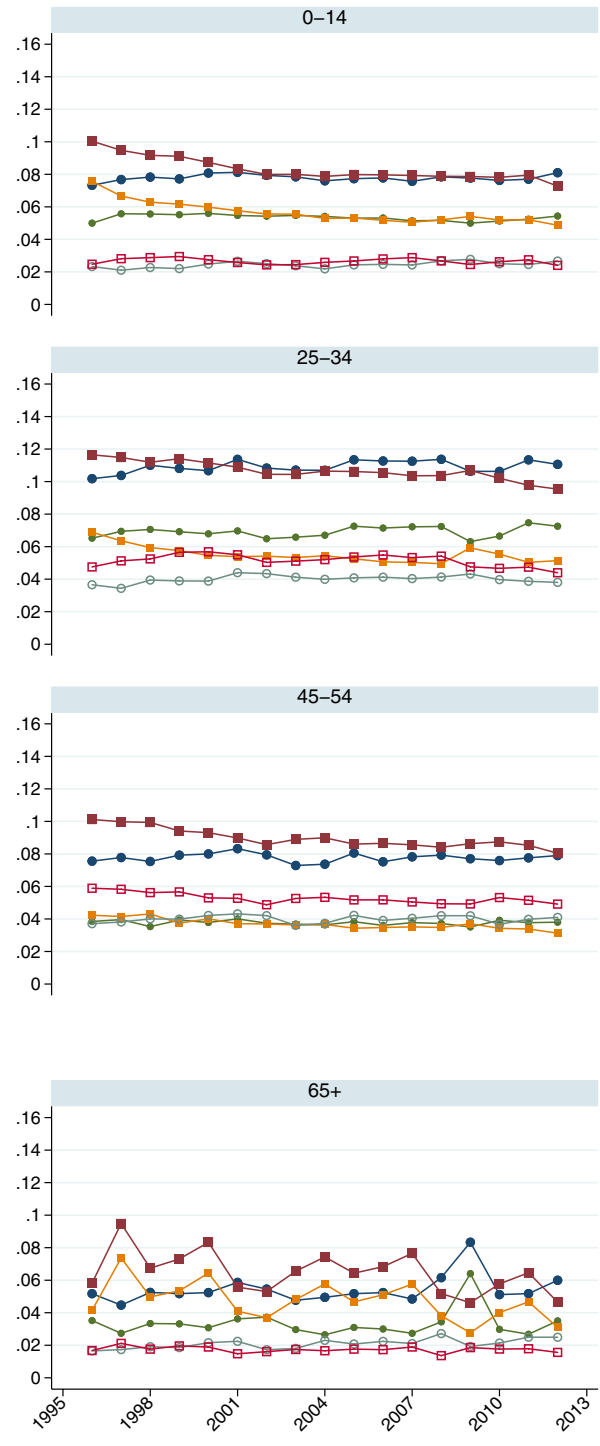

\begin{tabular}{llll}
$\longrightarrow$ & Inflow to middle class & - & Outflow from middle class \\
$\square$ & In: Low to Mid & Out: Mid to Low \\
- & In: High to Mid & $\square$ & Out: Mid to High \\
\hline
\end{tabular}

Graphs by age_group

Fig. 5 Directional mobility by primary activity. Flows are measured as the share of individuals with a corresponding change in income group status. Estimates are relative to the size of an age group. Source: Based on data from Statistics Finland (2014) 


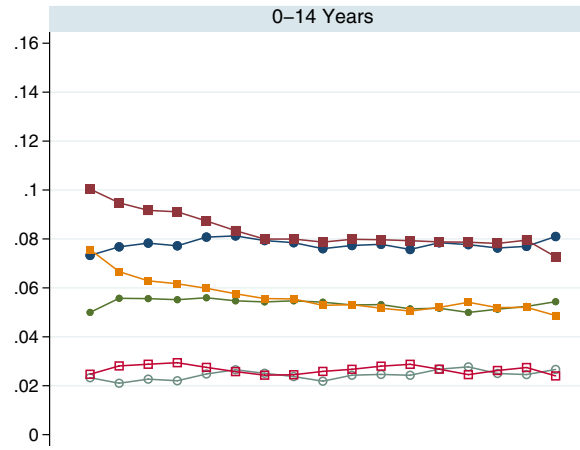

Outside of workforce

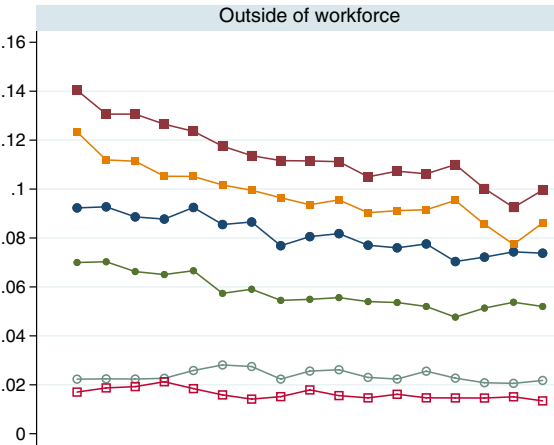

Students

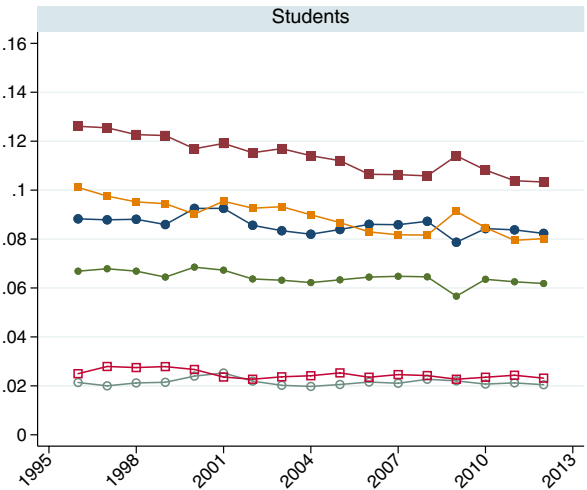

Employed
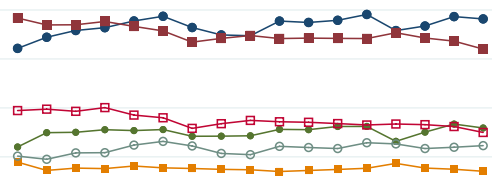

Retired

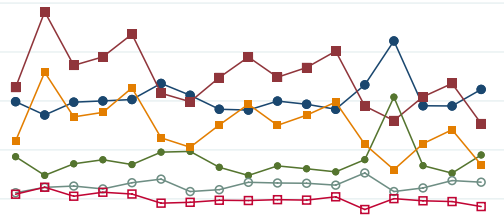

Unemployed

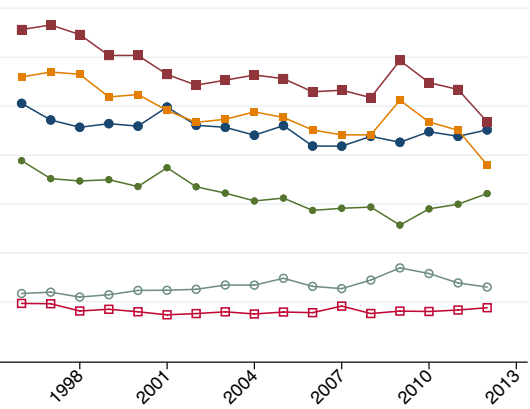

\begin{tabular}{|lll|}
$\square$ & Inflow to middle class & Outflow from middle class \\
\hdashline & In: Low to Mid & Out: Mid to Low \\
\hdashline & In: High to Mid & Out: Mid to High \\
\hline
\end{tabular}

Graphs by Primary

Fig. 6 Directional mobility by primary activity. Flows are measured as the share of individuals with a corresponding change in income group status. Estimates are relative to the size of a primary activity group. Source: Based on data from Statistics Finland (2014) 


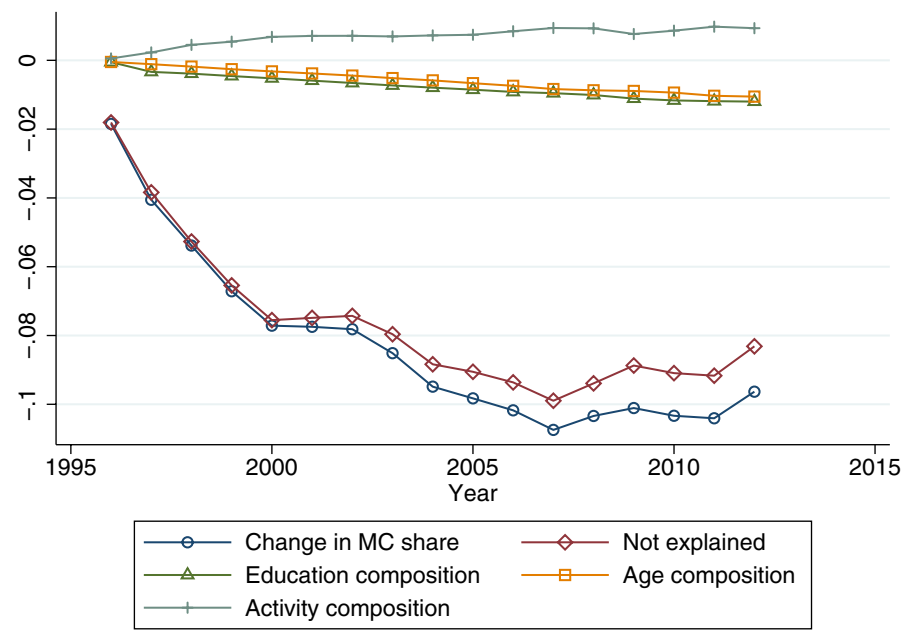

Fig. 7 Decomposition of changes in the middle-class population share following an extention of the Blinder-Oaxaca technique presented in Fairlie (2005) with coefficients from a pooled probit model. "Not explained" relates to the difference between Change in MC share and the explained part due to compositional changes. Instead of age categories, 3rd degree polynomial form is allowed for age. Stata-module fairlie used for the estimations (Jann 2006). Source: Based on data from Statistics Finland (2014)

Acknowledgements I would like thank Jarkko Harju, Jani-Petri Laamanen and Matti Tuomala for their support, advice, and encouragement in this research project. Comments by the anonymous reviewer also significantly improved the paper. I would also like to thank Timo Heikkilä, Merja Kauhanen, Kaisa Kotakorpi, Jenni Laaksonen, Ilpo Suoniemi and Elina Tuominen for their valuable comments, as well as the seminar participants in the ECINEQ Winter School on Inequality and Social Welfare Theory 2019 in Alba di Canazei, the FDPE Public Economics and Labour Economics Workshop II/2018 in Helsinki, the 36th Summer Seminar of Finnish Economists in Jyväskylä, and the 76th Annual Congress of the IIPF.

Open Access This article is licensed under a Creative Commons Attribution 4.0 International License, which permits use, sharing, adaptation, distribution and reproduction in any medium or format, as long as you give appropriate credit to the original author(s) and the source, provide a link to the Creative Commons licence, and indicate if changes were made. The images or other third party material in this article are included in the article's Creative Commons licence, unless indicated otherwise in a credit line to the material. If material is not included in the article's Creative Commons licence and your intended use is not permitted by statutory regulation or exceeds the permitted use, you will need to obtain permission directly from the copyright holder. To view a copy of this licence, visit http://creativecommons.org/licenses/by/4.0/.

\section{References}

Atkinson, A. B., \& Brandolini, A. (2013). On the identification of the middle class. In J. C. Gornick \& M. Jäntti (Eds.), Income inequality: Economic disparities and the middle class in affluent countries (pp. 77-100). Stanford, California: Stanford University Press.

Banerjee, A., \& Duflo, E. (2008). What is middle class about the middle classes around the world? Journal of Economic Perspectives, 22(2), 3-28.

Blinder, A. S. (1973). Wage discrimination: Reduced form and structural estimates. Journal of Human Resources, 8(4), 436-455.

Burkhauser, R. V., Cutts, A. C., Daly, M. C., \& Jenkins, S. P. (1999). Testing the significance of income distribution changes over the 1980 s business cycle: A cross-national comparison. Journal of Applied Econometrics, 14(3), 253-272.

Bussolo, M., Davalos, M. E., Peragine, V., \& Sundaram, R. (2018). Toward a new social contract: Taking on distributional tensions in Europe and Central Asia. World Bank Publications. 
Chauvel, L. (2013). Welfare regimes, cohorts and the middle classes. In J. C. Gornick \& M. Jäntti (Eds.), Income inequality: Economic disparities and the middle class in affluent countries (pp. 115-141). Stanford, California: Stanford University Press.

Cho, L.-J., Retherford, R. D., et al. (1973). Comparative analysis of recent fertility trends in east asia. In: Proceedings of the 17th General Conference of the IUSSP. Vol. 2. IUSSP Liège, pp. 163-181.

Das Gupta, P. (1978). A general method of decomposing a difference between two rates into several components. Demography, 15(1), 99-112.

Das Gupta, P. (1993). Standardization and decomposition of rates: A user's manual. No. 186. US department of commerce, economics and statistics administration, Bureau of the Census.

Davidson, R. (2018). Statistical inference on the Canadian middle class. Econometrics, 6(1), 14.

Deutsch, J., Silber, J., \& Yalonetzky, G. (2014). On bi-polarization and the middle class in latin America: A look at the first decade of the twenty-first century. Review of Income and Wealth, 60, S332-S352.

Easterly, W. (2001). The middle class consensus and economic development. Journal of Economic Growth, 6(4), 317-335.

Fairlie, R. W. (1999). The absence of the african-american owned business: An analysis of the dynamics of self-employment. Journal of Labor Economics, 17(1), 80-108.

Fairlie, R. W. (2005). An extension of the blinder-oaxaca decomposition technique to logit and probit models. Journal of economic and social measurement, 30(4), 305-316.

Foster, J. E., \& Wolfson, M. (2010). Polarization and the decline of the middle class in Canada and the USA. Journal of Economic Inequality, 8, 247-273.

Galor, O., \& Zeira, J. (1993). Income distribution and macroeconomics. Review of Economic Studies, 60(1), 35-52.

Grabka, M. M., \& Frick, J. R. (2008). The shrinking German middle class: Signs of long-term polarization in disposable income? DIW Weekly Report, 4(4), 21-27.

Jann, B. (2006). FAIRLIE: Stata module to generate nonlinear decomposition of binary outcome differentials. Statistical Software Components, Boston College Department of Economics. https://ideas.repec. org/c/boc/bocode/s456727.html

Jäntti, M., Riihelä, M., Sullström, R., \& Tuomala, M. (2010). Trends in top income shares in Finland. In A. B. Atkinson, \& T. Piketty (Eds.), Top Incomes: A Global Perspective (pp. 371-447). Oxford University Press.

Jenkins, S. P. (1995). Did the middle class shrink during the 1980s? UK evidence from Kernel density estimates. Economics Letters, 49, 407-413.

Kitagawa, E. M. (1955). Components of a difference between two rates. Journal of the American Statistical Association, 50(272), 1168-1194.

López-Calva, L. F., \& Ortiz-Juarez, E. (2014). A vulnerability approach to the definition of the middle class. Journal of Economic Inequality, 12(1), 23-47.

Oaxaca, R. (1973). Male-female wage differentials in urban labor markets. International Economic Review, 14(3), 693-709.

Pressman, S. (2007). The decline of the middle class: An international perspective. Journal of Economic Issues, 41(1), 181-200.

Riihelä, M., \& Tuomala, M. (2019). Polarisaatiosta ja keskiluokan kuihtumisesta. Yhteiskuntapolitiikka, 84(2), 214-225.

Statistics Finland, (2014). Suomen virallinen tilasto (svt) (finnish official statistics): Tulonjaon kokonaistilasto (total statistics on income distribution), tuloerot 2014, laatuseloste: Tulonjaon kokonaistilasto.

Thurow, L. C. (1984). The Disappearance of the Middle Class. New York Times Feb 51984.

Publisher's Note Springer Nature remains neutral with regard to jurisdictional claims in published maps and institutional affiliations. 